\title{
A propósito del centenario del 711. Apuntes sobre método de la Arqueología de la Arquitectura $^{1}$
}

\author{
Luis CABALlero ZoredA \\ Instituto de Historia \\ Consejo Superior de Investigaciones Científicas. Madrid \\ luis.caballero@cchs.csic.es
}

En homenaje a mi amiga y colega Sally Garen In memory to my friend and colleague Sally Garen

Deseo en primer lugar agradecer al Departamento de Historia del Arte I de la Facultad de Geografía e Historia de la Universidad Complutense, organizador de esta reunión, su invitación para participar en ella. Se me ha sugerido que trate de la metodología que utilizo aunque en relación con el tema que aquí nos trae, esto es con el análisis de las consecuencias a que dieron lugar los hechos acaecidos en el año 711.

Inicio el tema enmarcando mi presencia en el lugar donde nos encontramos. Al fin y al cabo mi profesión es la de arqueólogo, distinta a la de historiador del arte que aquí se profesa. Ello valora para mí más si cabe la invitación que se me hace. Pero me obliga a encuadrar mi postura, sobre todo teniendo en cuenta algunas opiniones que han surgido últimamente y que discrepan de la actividad de la Arqueología con respecto a campos tradicionalmente estudiados por la Historia del Arte, como es el de la Arquitectura ${ }^{2}$.

\footnotetext{
${ }^{1}$ Este trabajo se ha realizado dentro del marco del proyecto de investigación titulado "Análisis Arqueológico de la Arquitectura Alto Medieval en Asturias: prospección, estratigrafía y cronotipología”, HUM2007-61417/ HIST, dirigido por quien lo firma y financiado por el Ministerio de Educación y Cultura. luis.caballero@cchs. csic.es

2 E. CARRERO SANTAMARÍA, "Teoría y método en la Historia de la Arquitectura Medieval. Algunas reflexiones", en G. ROSELLÓ BORDOY (coord.), Seminari d'estudis històrics 2007, Arqueologia de l'arquitectura, Palma de Mallorca, 2008, pp. 5-27. G. BOTO VARELA, y A.M. MARTíNEZ TEJERA, "Historiar la Arquitectura medieval. Intersecciones epistemológicas de la Historia del Arte y la Arqueología de la Arquitectura", Arqueología de la Arquitectura, 7 (2010), pp. 263-275. Carrero, aunque cita una abundante bibliografía arqueológica, sigue en su crítica las opiniones de García Granados, al que, a mi parecer y cuando menos, saca de contexto y malinterpreta sus opiniones. J. A. GARCÍA GRANADOS, "Historia del Arte y Arqueología: a propósito de arquitectura", Coloquio hispano-italiano de arqueología medieval (1990), Granada, 1992, pp. 61-80.
} 
La Arqueología estudia manifestaciones materiales de la cultura, como hace la Historia del Arte, utilizando para ello unos métodos específicos, la estratigrafía y la tipología. Estos métodos han tenido un proceso de lenta formación a lo largo del s. $\mathrm{XX}$ a la vez que se precisaba mi profesión y se diferenciaban sus objetivos, principios y metodología de otras vecinas, entre ellas de la Historia del Arte de la que en parte había surgido. Ello da lugar a que exista entre estas disciplinas una indefinición historiográfica y de sus campos de análisis que llega hasta nuestros días.

Personalmente me considero heredero de una ya lejana generación de historiadores en los que no se podía diferenciar con claridad el historiador del Arte del arqueólogo e incluso del arquitecto, de la que formaban parte Gómez-Moreno, Lampérez, Puig i Cadafalch, Torres Balbás. Y de otra, más cercana, diferenciada ya netamente como de arqueólogos aunque entre ellos variaran también sus formaciones y encuadres, como Camps Cazorla, Íñiguez Almech, Schlunk, Hauschild y Palol i Salellas. Todos ellos han estudiado los edificios. Todos ellos, sin embargo, se han considerado arqueólogos aunque procedieran de profesiones diferentes y utilizaran medios distintos. Del mismo modo, en mi ya larga experiencia investigadora, he alternado el análisis estilístico, propio de la Historia del Arte, con la estratigrafía y la tipología propias de la Arqueología.

En esta evolución, la Arqueología ha tenido un punto de inflexión muy significativo. En la década de los años 70 del siglo pasado, la Arqueología, que había organizado Wheeler veinte años antes, sufrió en Inglaterra una revolución resultado de la lenta maduración de su método que se denomina "método Harris" gracias al arqueólogo que lo transformó en el que hoy usamos en 1979, no hace aún medio siglo3. Los principios de la Arqueología siguen siendo los mismos, pero esta variante metodológica provocó un salto cualitativo diferenciando un antes y un después:

- Se abandona la excavación en catas por la excavación en área;

- Se sustituye la documentación escrita en un diario por el uso individualizado para cada estrato de fichas analíticas;

- Por lo tanto, se obliga a la numeración de referencia de todos los estratos;

- Para representar gráficamente los estratos se sustituye el dibujo de los cortes de algunos de ellos en las paredes de las catas por la planta de todos ellos;

- Y se introduce el uso del diagrama (o matrix Harris) que recupera la unidad analítica del yacimiento, descompuesto previamente, organizando la sucesión estratigráfica en una secuencia de etapas cronológicas.

3 M. WHEELER, Arqueología de campo, Madrid, Fondo de Cultura Económica, 1979 (primera edición 1954). E.C. HARRIS, Principios de estratigrafía arqueológica, Barcelona, Editorial Crítica, 1991 (primera edición 1979). La revolución Harris ocurre específicamente en Inglaterra. Arqueólogos italianos como Lamboglia y Carandini se pueden considerar los de la Europa meridional que corresponden a este cambio. A. CARANDINI, Historias en la tierra. Manual de excavación arqueológica, Barcelona, Editorial Crítica, 1997. También es recomendable la Introduzione de D. MANACORDA a la traducción italiana de E.C. HARRIS, Principi di Stratigrafia Archeologica, Urbino, La Nuova Italia Scientífica, 1989, pp. 9-36. 

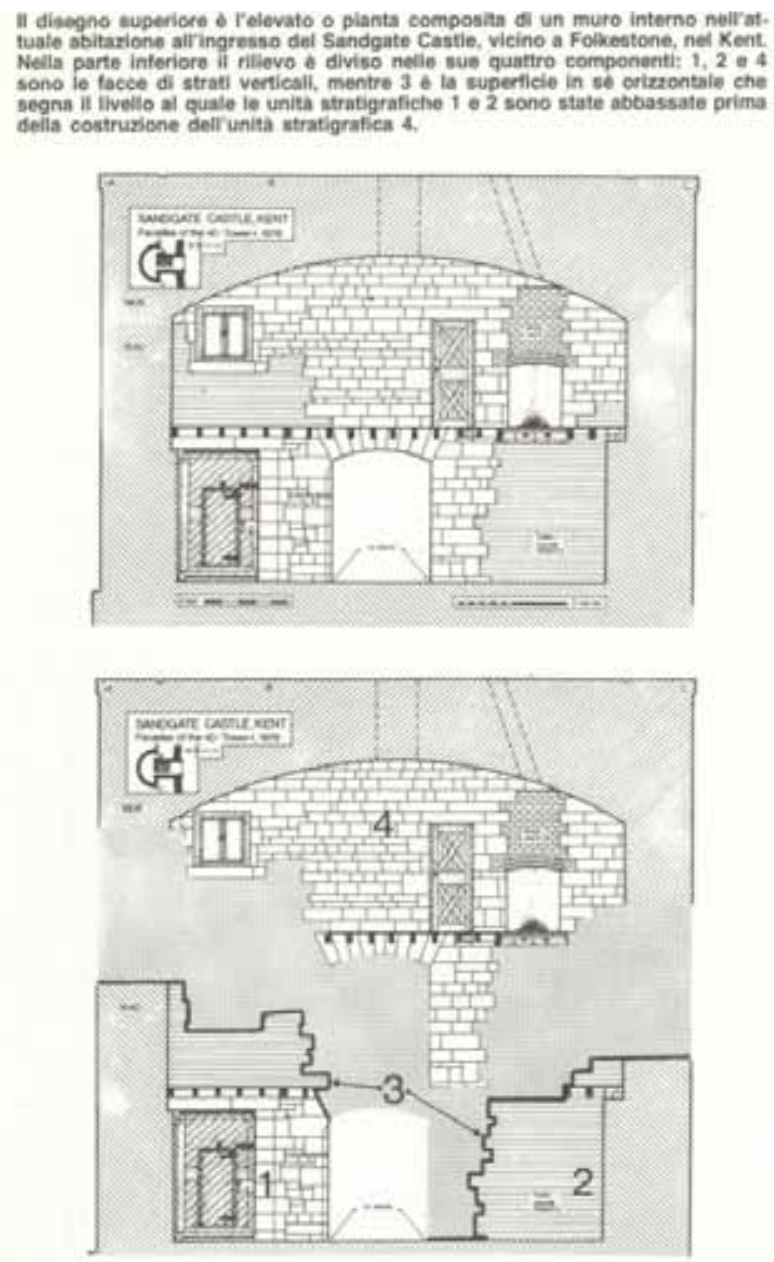

Fig. 1. Sandgate Castle, Kent. Primera experiencia de Arqueología de la Arquitectura [E.C. HARRIS, Principi di Stratigrafia Archeologica, Urbino, La Nuova Italia Scientífica, 1989, fig. 12].

Enfrentado a la complejidad que supone el estudio del yacimiento estratificado, el método Harris automatiza la observación, la descripción y el mismo análisis ${ }^{4}$. Como método arqueológico propiamente dicho, es más ordenado y riguroso en la obtención

4 Se suele decir que "es más objetivo", pero no es adecuado aplicarle esta denominación de "objetivo", dado que todo proceso investigador es de por sí subjetivo y el problema de la objetividad se resuelve de otro modo. L. CABALLERO ZOREDA, "Sobre Historia y Restauración del Monumento (o de la diferencia entre S. Juan de Baños y el Taj Mahall)", I Bienal de la Restauración Monumental. Diputació de Barcelona. Academia del Partal (L'Hospitalet de Llobregat, Barcelona), Quaderns Científics i Tècnics de Restauració Monumental, 13 (2002), pp. 41-52. 
y en el análisis de los datos que sus precedentes y por ello se trata de un instrumento de mayor calidad heurística y hermeneútica, o sea, tiene mayor capacidad analítica.

Harris, en sus "Principios", ya propuso la aplicación de su método al estudio de la arquitectura histórica partiendo de un principio de unidad de la cultura material (fig.1). El yacimiento surge como consecuencia de la continua actividad constructiva humana, de modo que edificio y yacimiento tienen el mismo origen y desarrollo. Es lógico que a ambos se les aplique el mismo método de análisis. Investigadores italianos como Mannoni (ingeniero), Parenti (arquitecto e historiador del arte), Brogiolo (arqueólogo e historiador) y Doglioni (arquitecto) han desarrollado esta aplicación que se denomina Arqueología de la Arquitectura y que es fundamentalmente similar a la utilizada para el subsuelo ${ }^{5}$. El objeto (estratos y muros), objetivos, instrumentos y aplicación metodológica son los mismos. Si para su uso excavador no se pone en duda su terminología específica (unidades, actividades, acciones), ni sus instrumentos (fichas analíticas, numeraciones, diagramas), ni su proceso, ni sus resultados, supone una ingenuidad dudar de su aplicación al edificio. La aceptación de su uso para el edificio aéreo debe ser tan universal como lo es para su infraestructura y su subsuelo.

No es raro que, dedicadas al estudio de la arquitectura, se descubran en la Historia del Arte y en la Arqueología similitudes derivadas por una parte del mismo objeto de estudio y de objetivos similares y por otra de que comparten un origen común. Las semejanzas atañen a sus métodos, pues ambos son de carácter filológico, e incluso a algunos instrumentos de análisis. Pero ello no debe engañarnos con respecto a la diferenciación metodológica que hoy existe entre ellas producida en gran parte por el desarrollo divergente de la Arqueología. No entro en la situación de la Historia del Arte por razones obvias ya que no me compete a mí, pero no será difícil inferir las diferencias observando a lo que atiende la Arqueología.

El método arqueológico y sus instrumentos están preparados para distinguir en los yacimientos y en los edificios horizontes diacrónicos. La estratigrafía distingue siempre en los edificios estratos, en muchos casos muy abundantes. Por eso digo que los edificios históricos son pluri-estratificados. Bajo la apariencia de un edificio unitario se esconde la adición sistemática de partes de otros mutilados en un reiterado proceso de destrucciones y reconstrucciones. Por eso también afirmo, genéricamente, que no existen "edificios modelo" sino "estructuras reales". Aun los edificios más recientes o los más simbólicos, y por ello supuestamente menos maltratados, presentan reformas. Por su parte, la tipología (que no se debe confundir con el estilo) está estrechamente ligada a la estratigrafía porque a cada estrato pertenecen (como los fósiles guía de la Geología) tipos propios y característicos, y, del mismo modo, a cada tipo corresponden grupos de estratos coetáneos y correlacionados. Me refiero tanto a los aparejos como a los elementos y las formas que pertenecen a modos de hacer, talleres o sistemas constructivos determinados. Relacionadas entre sí, estratigrafía y tipología se "interdatan" de modo que las tipologías, abiertas y en continua revisión, aportan da-

5 Un estado de la cuestión con opiniones y bibliografía actual en Arqueología aplicada al estudio e interpretación de edificios históricos. Últimas tendencias metodológicas, Madrid, 2010, Ministerio de Cultura. También sobre los grupos españoles en la revista Arqueología de la Arquitectura, editada por la Universidad del País Vasco y el Consejo Superior de Investigaciones Científicas, http://arqarqt.revistas.csic.es 
taciones llamadas absolutas a las secuencias de cronología relativa de los diagramas estratigráficos. Además, la Arqueología, aunando las características de ambos métodos, desarrolla distintas líneas de análisis. Observa hiatos y cambios como etapas de obra, proyectos o intervenciones que responden a hechos o transformaciones sociales de muy diversa importancia y significado. Y desarrolla estudios de la producción constructiva. Esto permite elaborar una Historia de la Arquitectura nueva, distinta a la tradicional, no centrada en la teoría de los estilos sino en la evolución de los sistemas técnicos y de producción de la Arquitectura.

Las diferencias cada vez más notables entre Historia del Arte y Arqueología y la concurrencia de sus profesionales en el mismo campo de trabajo están dando lugar a que afloren problemas de rivalidad profesional.

La actividad excavadora y la necesaria especialización técnica que conlleva, normativizada legalmente para el ejercicio de la intervención, dan pábulo a la opinión de que el arqueólogo está limitado por el horizonte del suelo, discriminado únicamente a la infraestructura y a su ajuar cerámico asociado. Esta idea es falsa. El ámbito de la cultura material arquitectónica es común no sólo a historiadores del arte y a arqueólogos sino también a otros profesionales, a los arquitectos, dedicados a su historia o a su restauración, a los documentalistas, historiadores de fuentes y epigrafistas, a los analistas, físicos y químicos, y a los restauradores, cada uno con su bagaje metodológico y sus propios paradigmas y modelos explicativos. Para mí, opinar de otro modo, considerando que se debe diferenciar y limitar tajantemente el objeto de nuestras disciplinas, encierra el propósito interesado de restringir la libertad de estudio.

Al contrario, la divergencia producida entre Historia del Arte y Arqueología, en el campo de la Arquitectura, amplía el abanico de especializaciones metodológicas, a las que sería absurdo renunciar ${ }^{6}$. Los arqueólogos debemos la estratigrafía a los geólogos sin que ello haya supuesto la reivindicación academicista y exclusivista del método por unos u otros. Por mi parte, he defendido y procurado reiteradamente que los arquitectos dedicados al estudio de la Arquitectura (historiadores de la arquitectura) o a su restauración consideren la estratigrafía como un método propio de su profesión ${ }^{7}$. De hecho esto ya ocurre en algunas escuelas arquitectónicas donde se utiliza con éxito. Dado que considero que el actual método arqueológico es una herramienta heurística rigurosa y eficaz, mi obligación es procurar su expansión a otras ramas del saber y a disciplinas limítrofes que estén preparadas para su utilización. Por ello me atrevo aquí a sugerir y a ofrecer su utilización también a los historiadores del Arte,

6 Parangonando lo dicho por J.A. GARCÍA GRANADOS, op. cit; 1992, p. 68, las posiciones de la Historia del Arte y de la Arqueología, como la de la Arquitectura, no son necesariamente excluyentes: cómo se integran para ofrecer una nueva historia dependerá del rigor de las investigaciones futuras.

7 L. CABALLERO ZOREDA, “Arqueología y Arquitectura. Análisis arqueológico e intervención en edificios históricos", en C. FONTELA SAN JUAN, (coord.), Curso Actuacións no Patrimonio construido: un diálogo interdisciplinar, Santiago de Compostela, 1997, pp. 457-469. Idem, "Arqueología de la Arquitectura. Conocimiento y restauración", AR\&PA, Actas del IV Congreso Internacional "Restaurar la Memoria". Arqueología, Arte y Restauración (2004), Valladolid, 2006, pp. 161-179. 
aunque, como es obvio, deberá acomodarse "instrumentalmente" a su metodología propia, igual que lo han hecho a la suya los arquitectos ${ }^{8}$.

Sólo hay un límite a la utilización del método arqueológico y este límite es su uso correcto. Este método tiene su terminología y sus instrumentos específicos, que pueden resultar de una aparente complejidad para quien los desconoce. Es lógico. Pero ello no le descalifica; al contrario, obliga a quien lo va a utilizar, ya sea para analizar o para comprender sus resultados, a la aceptación de sus normas y a la voluntad de efectuar un mínimo esfuerzo de comprensión, como ocurre con cualquier campo profesional en el que se sea novato y del que se desee sacar provecho. Utilizarlo supone la aceptación de sus normas, su aprendizaje mediante su práctica y su aplicación correcta. Aseguro que esto no es complicado ni requiere un esfuerzo extra. El método no tiene nada de críptico. Su uso no es difícil, ni tedioso, sino, al contrario, implica una eficaz ayuda en el trabajo de campo y entusiasma cuando se comprueba su potencialidad. Su complicación es aparente, producida más por el modo de trabajo que normalmente se debe realizar en equipo.

Que reconozca el rigor del actual método de la Arqueología no supone que yo minusvalore los métodos de otras disciplinas de un modo perverso y excluyente. Que los métodos de otras disciplinas sean rigurosos no me obliga a abandonar el rigor de la mía. No se puede subestimar un método porque sea riguroso.

\section{$* * *$}

Doy por conocido el hecho de que en el año 1994 planteé un paradigma o modelo explicativo, distinto al aceptado tradicionalmente, que afecta a las llamadas "iglesias visigodas", proponiendo que en vez de construirse en el s. VII lo habrían sido después del 711, dos de ellas inmediatamente en el s. VIII y el resto del grupo en la etapa feudal altomedieval, en los siglos IX y $\mathrm{X}^{9}$. Este cambio se relaciona estrechamente con el hecho histórico del año 711 pues sería justamente la llegada islámica la que, según mi propuesta, abriría un "canal de transmisión de lo clásico" que explicaría la aparición de las características novedosas de esta arquitectura (sillería, decoración arquitectónica, abovedamiento y plantas compartimentadas). Mi explicación plantea una ruptura con la aceptada tradicionalmente que supone la continuidad entre el mundo clásico, esta arquitectura considerada visigoda, potenciada por un influjo externo bizantino, y las arquitecturas altomedievales. Para mí, la arquitectura asturiana también debe su presencia, en último término, a la apertura del canal islámico u omeya.

El cambio de paradigma lleva aparejado comprobar la teoría tradicional, que hasta ese momento había defendido, y falsar o rebatir la nueva expuesta. Para ello se necesita un método nuevo. Un cambio de paradigma supone la existencia de un nuevo método que permita la observación de datos distintos a los adquiridos con el método tradicional que no por ello pierde su virtualidad. La revolución producida en la

\footnotetext{
8 A título de ejemplo, L. CÁMARA, "Estratigrafía, evolución estructural y restauración. El caso de la iglesia de Santa Eulalia en Marquínez (Álava)", Arqueología de la Arquitectura, 7 (2010), pp. 225-260.

9 L. CABALLERO ZOREDA, "Un canal de transmisión de lo clásico en la alta Edad Media española. Arquitectura y escultura de influjo omeya en la Península Ibérica entre mediados del s. VIII e inicios del X", Al-Qantara, 15-16, (1994-95), pp. 321-348 y pp. 107-124.
} 
Arqueología por el método Harris y su aplicación a la arquitectura proporcionaba este método que me preocupé de aprender, introducir en nuestro campo de estudio y potenciar.

$\mathrm{Al}$ asegurar que el actual método arqueológico es más riguroso que el anterior, se aplique o no al estudio de la arquitectura, quiero decir que no sólo es más propio y preciso, sino también que es más ordenado (esto es, metódico y sistemático), neutro, completo (para el objeto que se analiza) y relacional (esto es, que muestra las relaciones que existen entre sus partes). Estas características se dan en cada uno de los ejemplos que expongo a continuación y las doy por supuesto sin detenerme en cada caso a explicitarlas.

Por otra parte, la situación provocada por la propuesta del nuevo paradigma me obligó a realizar estudios monográficos de los edificios antes de poder sintetizar las conclusiones que se obtuvieran de ellos. A estos estudios me he dedicado en la última década, lo que explica de alguna manera el esquema de esta intervención. Las características del método, riguroso, ordenado, neutro, completo y relacional, se reflejan a su modo en el análisis de cada edificio dando lugar a estos arquetipos:

- Edificio y yacimiento forman una misma unidad y por lo tanto una misma secuencia completando sus informaciones cronológicas y funcionales;

- Descripción correcta del edificio. La aplicación del método distingue todas las unidades de que está compuesto, las diferencia, describe, nombra y relaciona entre sí. Supone modificar su concepción como "edificio modelo" a su comprensión como una "estructura real" transformada por la adición de distintos originales conservados parcialmente. Es el rasgo más universal de su aplicación;

- Ruptura del punto muerto historiográfico y catalogación correcta. El resultado de la lectura estratigráfica aclara la adscripción cronológico-cultural;

- La producción constructiva y el producto construido. La descripción estratigráfica de un edificio o conjunto unitario y sincrónico describe, disecciona y analiza su proceso técnico de producción;

- Construcción y decoración. La decoración es un elemento singular del producto constructivo que se somete a parecidas normas.

Como consecuencia de la propuesta de un nuevo paradigma, procuré poner en marcha un "programa de investigación". Tras la documentación planimétrica de los edificios, la principal estrategia de este programa es la del registro arqueológico de los edificios concernidos. Pero no debe entenderse sólo como el desarrollo de una estrategia estratigráfica, ya que esta se relaciona con las tipológicas de aparejos, formas constructivas, decoraciones y elementos litúrgicos, entre otras, así que en realidad es estratigráfica y tipológica. Estas estrategias han tomado su propia independencia de modo que van precisando el paradigma propuesto. 


\begin{tabular}{|ll|}
\hline Santa Comba de Bande & Orense \\
San Salvador de Valdediós & Asturias \\
Santo Adriano de Tuñón & Asturias \\
San Miguel de Lillo & Asturias \\
Santianes de Pravia & Asturias \\
Santa Coloma & La Rioja \\
Santa María de los Arcos, Tricio & La Rioja \\
Suso, San Millán de la Cogolla & La Rioja \\
San Pedro el Viejo de Arlanza & Burgos \\
La Asunción. San Vicente del Valle & Burgos \\
Santa Cecilia. Tabladillo & Burgos \\
San Juan Bautista de Baños & Palencia \\
San Pedro de La Nave & Zamora \\
San Miguel de Escalada & León \\
Segóbriga. Saelices & Cuenca \\
San Pedro de La Mata & Toledo \\
Santa María de Melque & Toledo \\
El Gatillo & Cáceres \\
Santa Lucía del Trampal & Cáceres \\
Santiago de Alburquerque & Badajoz \\
Santa Eulalia de Mérida & Badajoz \\
São Gião de Nazaré & Leiria, Portugal \\
Sé de Idanha-a-Velha & Castelo Branco, Portugal \\
& \\
\end{tabular}

Cuadro 1. Un "programa de investigación”.

Una rápida pero necesaria visión historiográfica precisa mi postura ${ }^{10}$. Al margen de otros precedentes, fue Gómez-Moreno quien impuso los principios del modelo visigotista definiendo la arquitectura "mozárabe" del valle del Duero, datándola en el s. X y excluyendo de esta fecha cualquier otro tipo de edificios ${ }^{11}$. Ubicó los edificios visigodos en el s. VII por las dataciones axiomáticas de Bande (por criterio documental) y Baños (por criterio epigráfico) ${ }^{12}$. Así procuraba también con los arcos de herradura ${ }^{13}$ y la escultura decorativa que encuadró en estos dos grupos arquitectónicos a los que a la vez servían de referencia. Posteriormente el hispanista alemán Schlunk pretendió cerrar los puntos débiles dejados por este esquema proponiendo

10 L. CABALLERO ZOREDA, "Acerca del paisaje arquitectónico hispánico inmediato al año 711 (entre Toledo y el territorio astur y vasco)", 711. Arqueología e Historia entre dos mundos, Zona Arqueológica, 15, Vol. 1, Alcalá de Henares, 2011, pp. 255-272.

11 M. GOMEZ-MORENO, Iglesias Mozárabes. Arte español de los siglos IX a XI, Madrid, Centro de Estudios Históricos, 1919. L. CABALLERO ZOREDA, "Vida y trabajo de Manuel Gómez-Moreno. Con la arquitectura alto medieval como tema", Coloquio Centenario del Centro de Estudios Históricos, Madrid, CCHS, CSIC, 2010, publicado en línea, http://hdl.handle.net/10261/33337.

12 M. GOMEZ-MORENO, "Primicias del arte cristiano español”, Archivo Español de Arte, 39 (1966), pp. 101-139.

13 M. GOMEZ-MORENO, "Excursión a través del arco de herradura”, Cultura Española, 3, (1906), pp. 785-811. 
argumentaciones forzadas sobre el influjo bizantino en la arquitectura y la decoración visigoda ${ }^{14}$. Su propuesta paradigmática es la más forzada: la existencia de una miniatura toledana del s. VII, desconocida pero necesaria para justificar la datación en esa fecha de la figuración de la iglesia de La Nave, pese a la existencia de similares modelos en la miniatura mozárabe del s. X y aunque su cronología la determinara un paralelo menor con Baños, necesario dada su considerada fecha del s. VII ${ }^{15}$. Una nueva generación de historiadores obvió los problemas mantenidos por estos autores con algunas de estas iglesias y reforzó la línea argumentativa seguida por ellos. Palol propuso un "grupo de transición" que permitiera el continuismo entre la arquitectura tardorromana y la visigoda ${ }^{16}$; Bango planteó la recuperación de la producción arquitectónica altomedieval gracias a la restauración e imitación de los edificios visigodos abandonados, lo cual es técnicamente imposible, y supuso la existencia de una arquitectura visigoda, desconocida pero necesaria para justificar la recuperada en el reino de Asturias ${ }^{17}$; y Arbeiter pretendió demostrar que la reutilización de sillares romanos en edificios tardoantiguos provocó la recuperación de la técnica de la sillería visigo$\mathrm{da}^{18}$. Argumentos parecidos utilicé por mi parte para justificar las fechas visigodas de Bande, Melque y El Trampal ${ }^{19}$.

El detonante que me sirvió para recusar este sistema historiográfico, sobre contradicciones previamente advertidas ${ }^{20}$, lo provocó Garen al proponer que la iglesia de Melque dependía de soluciones constructivas omeyas y por lo tanto cambiar su fecha del s. VII al s. VIII ${ }^{21}$. Esta atrayente propuesta me incitó a comprobar si también convenía al sistema formado por la arquitectura y la escultura visigoda en la que la iglesia se incluía. Así fue como planteé la nueva propuesta sobre la apertura del

14 H. SCHLUNK, "Relaciones entre la Península Ibérica y Bizancio durante la época visigoda", Archivo Español de Arqueología, 60 (1945), pp.177-204. Idem, “Arte visigodo. Arte asturiano", Ars Hispaniae, II, Madrid, 1947, pp. 325-416. Idem, y TH. HAUSCHILD, Die Denkmäler der frühchristlichen und westgotischen Zeit, Mainz am Rhein, 1978.

15 H. SCHLUNK, "Observaciones en torno al problema de la miniatura visigoda", Archivo Español de Arte, 71 (1945), pp. 241-265.

16 P de PALOL SALELLAS, Arqueología Cristiana de la España romana. Madrid-Valladolid, 1967.

17 I.G. BANGO TORVISO, "El neovisigotismo artístico de los siglos IX y X: la restauración de ciudades y templos", Revista de Ideas Estéticas, 148 (1979), pp. 319-338. Idem, "De la arquitectura visigoda a la arquitectura asturiana: los edificios ovetenses en la tradición de Toledo y frente a Aquisgrán”, L'Europe héritière de l'Espagne wisigothique, Madrid, 1992, pp. 303-313. Idem, "Los expolios del paisaje monumental y la arquitectura hispana de los siglos VII al XI. Reflexiones sobre el proceso constructivo de San Miguel de Escalada", De Arte, 7 (2008), pp. 7-50.

18 A. ARBEITER, "Construcciones con sillares. El paulatino resurgimiento de una técnica edilicia en la Lusitania visigoda”, IV Reunió d'Arqueología Cristiana Hispánica (Lisboa, 1992), Barcelona, 1995, pp. 211-221.

19 L. CABALLERO y J.I. LATORRE, La iglesia y el monasterio visigodo de Santa María de Melque (Toledo). Arqueología y arquitectura. San Pedro de la Mata (Toledo) y Santa Comba de Bande (Orense), Excavaciones Arqueológicas en España, 109. Madrid, 1980. Idem, et alii, "La iglesia de época visigoda de 'Santa Lucía del Trampal', Alcuéscar (Cáceres)", I Jornadas de Prehistoria y Arqueología en Extremadura (1986-1990), Extremadura Arqueológica, 2, Mérida, 1991, pp. 497-523.

20 L. CABALLERO ZOREDA, “¿Visigodo o asturiano? Nuevos hallazgos en Mérida y otros datos para un nuevo 'marco de referencia' de la arquitectura y la escultura altomedieval en el Norte y Oeste de la Península Ibérica”, 39 Corso di Cultura sull'Arte Ravennate e Bizantina, Rávena, 1992, pp. 139-190.

21 S. GAREN, "Santa Maria de Melque and Church Construction under Muslim Rule", Journal of the Society of Architectural Historians, 51-3 (1992), pp. 288-305. 
“canal de transmisión" islámico. El punto de arranque utilizado en 1994-1995 siguió un argumento basado especialmente en el estilo decorativo de la escultura visigoda y omeya, deudor del estado de la cuestión visigotista y del método de los que partí y que fue criticado desde el campo arqueológico ${ }^{22}$.

Inicio ahora un recorrido por el método siguiendo varios caminos paralelos. Ante todo, me veo obligado a presentar el resultado de aplicar el método a cada edificio por separado. Pero procuro ordenar de un modo coherente las estrategias metodológicas, las cronologías y los grupos de edificios. Además, los cuatro primeros casos ejemplifican mi propia conversión metodológica del sistema de excavación Wheeler, preharrisiano, al de registro arqueológico de Harris, como procuro ir señalando.

El experimento inicial de mi aplicación del método arqueológico "Harris" a la arquitectura se dio paradójicamente en la excavación de un subsuelo, el de la basílica martirial y funeraria de Santa Eulalia, modelo de la arquitectura tardoantigua urbana, situada en el suburbio de Mérida ${ }^{23}$. La utilización de la iglesia medieval como necrópolis hasta pleno $\mathrm{s}$. XX había hecho desaparecer la secuencia estratigráfica tardo antigua, medieval y moderna de su yacimiento, de modo que hubo que aplicar el sistema Harris de registro a los restos de cimientos e infraestructuras arquitectónicas, sistema que se aplicó también al alzado de la cabecera. De otro modo era imposible orientarse en el universo de fragmentos y restos constructivos encontrados. Así, es un ejemplo del carácter sistemático del método que permitió ordenar una secuencia continua desde mediados del s. I de la Era hasta nuestros días formada solamente por elementos arquitectónicos (fig. 2). El arrasamiento del yacimiento interior de la iglesia y de su estratigrafía había producido también la desaparición de cerámica y la necesidad de utilizar, cuando era posible, otras estrategias (tipológica y documental) para la datación de la secuencia.

Otra iglesia tardo antigua excavada antes de mi paso definitivo al sistema Harris, es la de El Gatillo de Arriba (Cáceres), quizás una parroquia rural ${ }^{24}$. Desde el punto de vista metodológico este trabajo es ejemplo de la virtualidad de este método dado que fue excavada siguiendo los preceptos preharrisianos y hubo que trasladar los datos del diario a la organización analítica y diagramática de Harris. La riqueza de la secuencia estratigráfica de sus muros da ejemplo de la característica relacional de es-

22 M. ACIÉN ALMANSA, "La herencia del protofeudalismo visigodo frente a la imposición del estado islámico", en L. CABALLERO y P. MATEOS (edits.) Visigodos y Omeyas. Un debate entre la Antigüedad tardia y la alta Edad Media, Anejos de AEspA, 23, Madrid, 2000, pp. 429-441.

23 P. MATEOS CRUZ, La basílica de Santa Eulalia de Mérida. Arqueología y Urbanismo, Anejos de AEspA, 19, Madrid, 1999. La basílica se construyó en la segunda mitad del s. V o inicios del VI, condicionada por la preexistencia de la memoria de la mártir Eulalia (inicios del s. IV) y sobre la necrópolis cristiana a que había dado lugar. Posteriormente fue reformada en 560/570.

24 L. CABALLERO y F. SÁEZ, "La iglesia de El Gatillo de Arriba (Cáceres). Apuntes sobre una iglesia rural en los siglos VI al VIII", en L. CABALLERO, P. MATEOS y M.Á. UTRERO (edits.) El siglo VII frente al siglo VII: Arquitectura, Anejos de AEspA, 51, Madrid, 2009, pp.155-184. Esta iglesia se construyó hacia finales del s. V. En su etapa III, su mausoleo lateral se convirtió en un complejo bautismal de forma basílical y tipología muy avanzada lo que permite datarlo después del 711. En su última etapa, durante el s. IX, se convirtió en una alquería. 

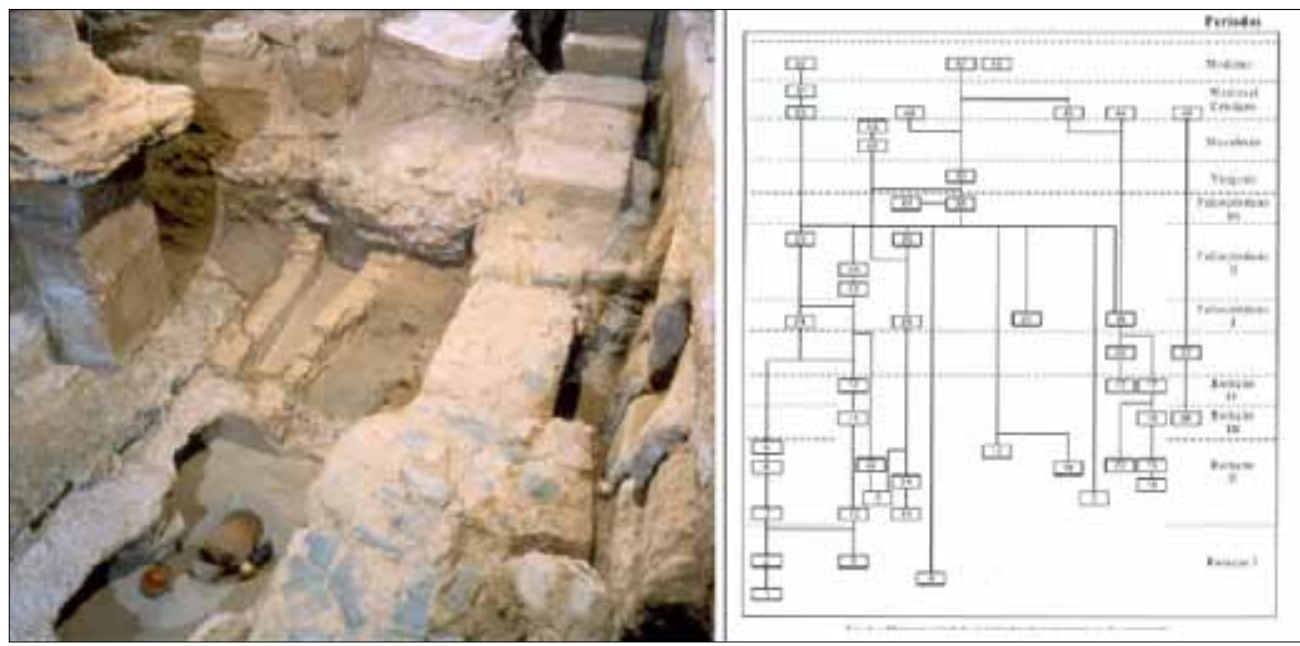

Fig. 2. Santa Eulalia de Mérida (Badajoz). Detalle de la excavación con restos romanos, paleocristianos, visigodos y medievales. Las relaciones físicas entre los elementos, "se adosa o se le adosa, rellena o le rellena, corta o es cortado y se superpone o se le superpone", ordenan cronológicamente los restos encontrados. La secuencia obtenida se ofrece en un diagrama de Actividades; entendiendo por tales grupos de Unidades Estratigráficas [P. MATEOS, La basílica de Santa Eulalia de Mérida, Anejos de AEspa, 19, Madrid, 1999].

tos trabajos. Por otra parte, esta iglesia es también modelo de la arquitectura basilical tardorromana, de aula cubierta de madera. Se puede considerar el tipo de iglesia habitual a la llegada del año 711, vieja doscientos o más años, aún en uso con reformas y adecuaciones y que perduraron aún un siglo más (fig. 3).

Traspaso ahora la frontera cronológica del año 711 con dos conjuntos monásticos, Santa María de Melque (San Martín de Montalbán, Toledo) y Santa Lucía del Trampal (Alcuéscar, Cáceres) ${ }^{25}$. En El Trampal, el registro arqueológico se tradujo, igual

25 L. CABALlERO y F. SÁEZ, La Iglesia Mozárabe de Santa Lucía del Trampal, Alcuéscar (Cáceres). Arqueología y Arquitectura, Memorias de Arqueología Extremeña, 2, Mérida, 1999. L. CABALLERO y J.I. LATORRE, op. cit; 1980. L. CABALLERO y M. FERNÁNDEZ, "Notas sobre el complejo productivo de Melque (Toledo). Prospección del territorio y análisis de carbono-14, polínicos, carpológicos y antracológicos y de morteros", Archivo Español de Arqueología, 72 (1999), pp. 199-239 [con la colaboración de A. Rubinos, R. Macías, P. López, A.M. Arnánz, P. Uzquiano y B. Guarás]. L. CABALLERO, M. RETUERCE y F. SÁEZ, "Las cerámicas del primer momento de Santa María de Melque (Toledo), construcción, uso y destrucción. Comparación con las de Santa Lucía del Trampal y El Gatillo (Cáceres)", en L. CABALLERO, P. MATEOS y M. RETUERCE (edits.), Cerámicas tardorromanas y altomedievales en la península Ibérica: ruptura $y$ continuidad, Anejos de AEspA, 28, Madrid, 2003, pp. 225-272. L. CABALLERO y F.J. MORENO, "Balatalmelc, Santa María de Melque. Un monasterio del siglo VIII en territorio toledano", Coloquio Internacional. Teoría y práctica fiscal en el Occidente islámico y en Dar al-islam (ss. VII-IX). Universitat de Barcelona (2010), Barcelona, e.p. Construidos ambos monasterios en la segunda mitad del s. VIII se abandonan durante el s. IX avanzado; Melque se transformó en un poblado islámico que pervivió hasta época cristiana, conservando su iglesia, mientras que El Trampal se abandonó hasta la tardía recuperación y restauración gótica de su iglesia y su posterior transformación en una casa de campo con la desamortización del s. XIX. 


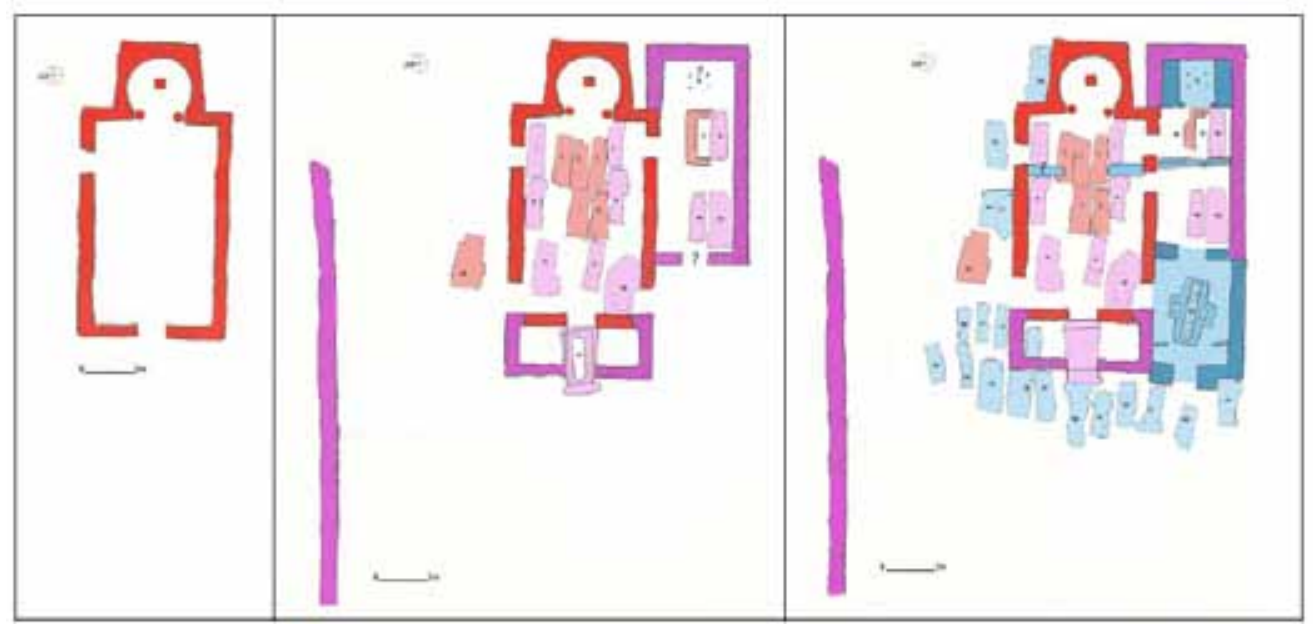

Fig. 3. El Gatillo (Cáceres). Tres estadios de una iglesia rural tardorromana.

Respectivamente en el momento de su construcción hacia 500 d.C.; en el s. VII, añadidos un porche-mausoleo a los pies y un espacio funerario al Sur; y a mediados del s. VIII, cuando los anexos meridionales se convierten en una basilicula bautismal

[L. CABALLERO y F. SÁEZ, "La iglesia de El Gatillo de Arriba (Cáceres). Apuntes sobre una iglesia rural en los siglos VI al VIII", en L. CABALLERO, P. MATEOS y M.Á.

UTRERO (edits.) El siglo VII frente al siglo VII: Arquitectura, Anejos de AEspA, 51, Madrid, 2009].

que en El Gatillo, de un sistema de diario preharrisiano al analítico y diagramático del método Harris. Además se utilizó conjuntamente el registro arqueológico de su yacimiento y de su arquitectura dando secuencias completas desde su construcción hasta nuestros días (fig. 4). El reconocimiento del proceso de construcción y ruina de su iglesia facilitó la reconstrucción de su compleja estructura arquitectónica y litúrgica. Por su parte, Melque es un ejemplo historiográfico de la aplicación asociada de métodos y modelos explicativos: primero del método estilístico y la explicación mozárabe de Gómez-Moreno a comienzos del s. XX; luego de paralelos de estilo y excavación preharrisiana y de mi primera explicación, visigoda, en los años setenta del mismo siglo; y finalmente del método de registro arqueológico Harris, que procura una información exponencialmente más rica que el anterior, y de mi segunda explicación como primer mozárabe o dimmi en el primer decenio de este siglo. La estrategia de datación cronológica utilizada en la última etapa es significativa. La excavación arqueológica descubrió en Melque los niveles de construcción del monasterio y la iglesia con huecos de andamios, pilas de amasado y niveles y restos de la construcción. De este modo se pueden contrastar las distintas dataciones obtenidas con la secuencia estratigráfica de sus niveles de construcción y suelos (cuadro 2). Resulta llamativa la imposibilidad de acordar con esta secuencia los abundantes análisis de carbono 14 realizados. Esta analítica no permite una datación concreta del monasterio debido a su situación en la curva de calibración y a otros problemas que eviden- 


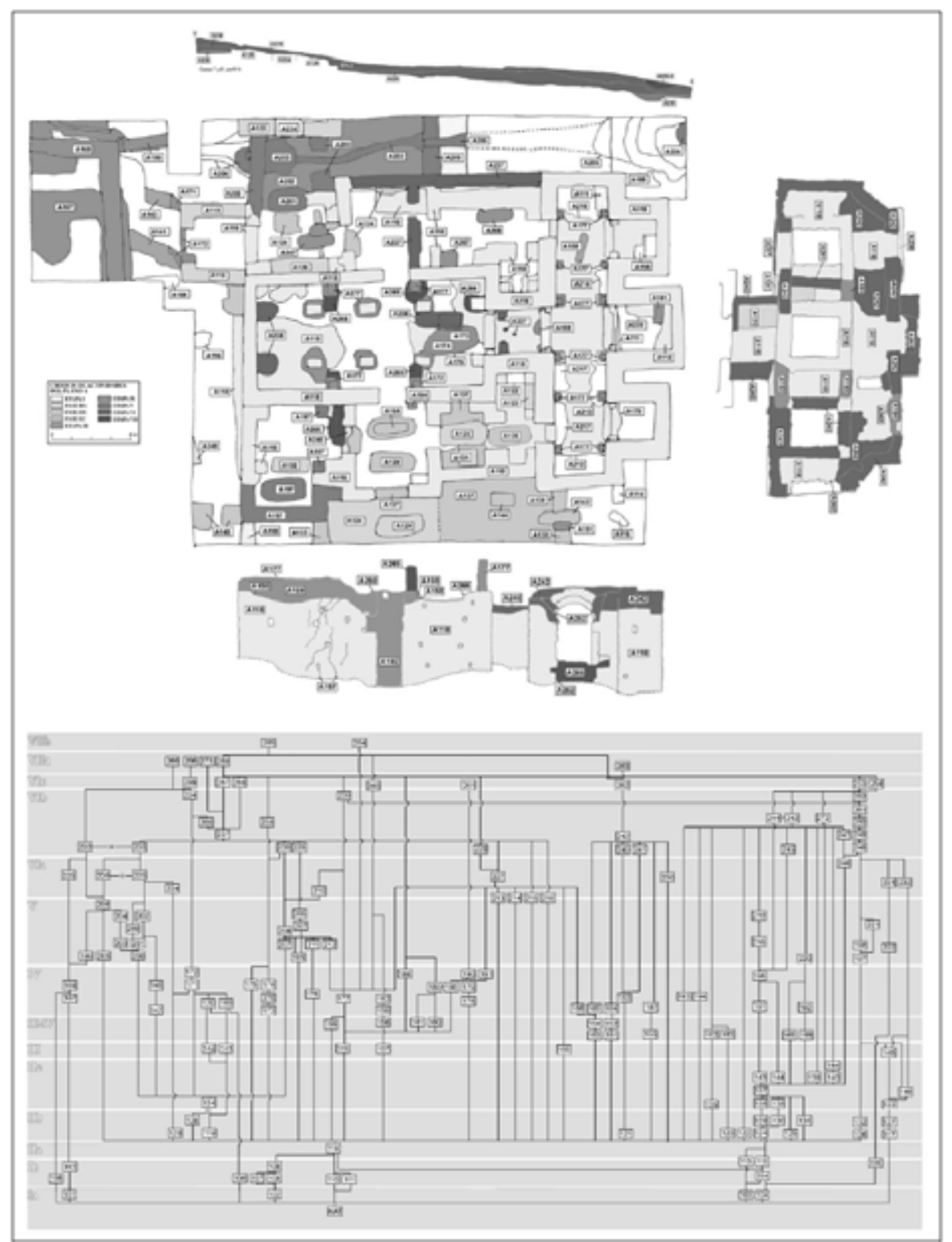

Fig. 4. Iglesia monástica de Santa Lucía del Trampal (Montánchez, Cáceres). El registro arqueológico, que abarca al yacimiento, la arquitectura y la excavación de la cubierta, ofrece una secuencia completa desde el momento de su construcción hasta la restauración contemporánea [L. CABALLERO y F. SÁEZ, La Iglesia Mozárabe de Santa Lucía del Trampal, Alcuéscar (Cáceres). Arqueología y Arquitectura, Memorias de Arqueología Extremeña, 2, Mérida, 1999]. 


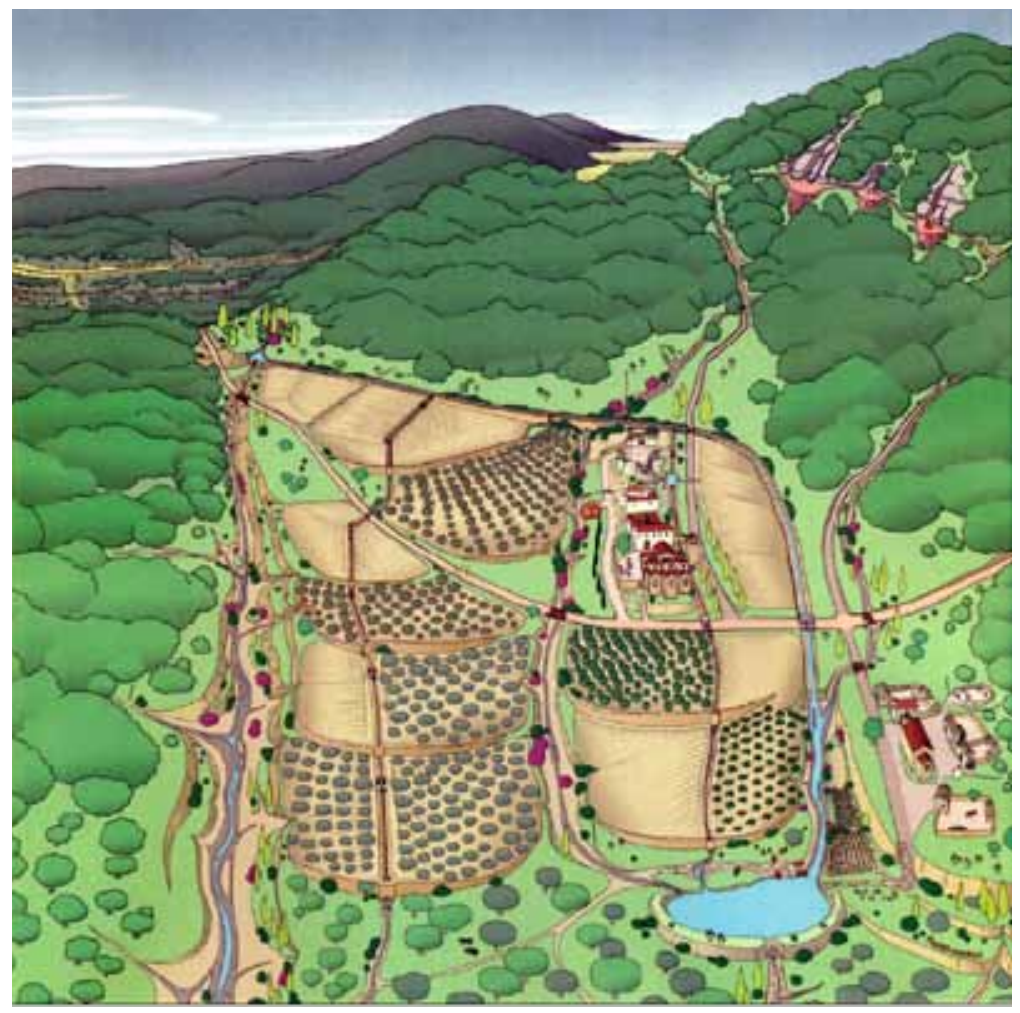

Fig. 5. Instalación hidráulica y explotación agrícola del monasterio de Santa Lucía del Trampal, junto a la "vía de La Plata” [Cáceres. Dibujo de Fernando Sáez].

cian sus limitaciones y el cuidado que debe tenerse con su correcta utilización ${ }^{26}$. Al contrario, la cerámica emiral data los conjuntos de Melque y El Trampal en el s. VIII. La arqueología del territorio de ambos asentamientos demuestra que se realizó una cuidadosa elección de sus ubicaciones de modo que se aprovecharon sus condiciones hidrográficas para crear instalaciones hidráulicas que permitieran mantener sus explotaciones agrícolas; Melque en un clima semiárido y El Trampal en otro húmedo (fig. 5). Además la Arqueología ha permitido conocer los principios ordenadores del conjunto monástico y de la liturgia de la iglesia en Melque y de sus posteriores modificaciones consecuencia de los sucesos violentos producidos por el proceso de islamización de su entorno ${ }^{27}$ (fig. 6). La descripción detallada de ambas iglesias ha

26 Un ejemplo de estos problemas y cómo resolverlos en A. VIGIL-ESCALERA, "Sepulturas, huertos y radiocarbono (siglos VIII-XIII d. C.). El proceso de islamización en el medio rural del centro peninsular y otras cuestiones", Los mozárabes entre la Cristiandad y el Islam, Stvdia Historica. Historia Medieval, 27 (2009), pp. 97-118.

27 El conjunto residencial del monasterio de Melque se ordenaba en tres núcleos, separados entre sí: uno público más exterior; otro propiamente monástico, del que conocemos los edificios de residencia y los de 

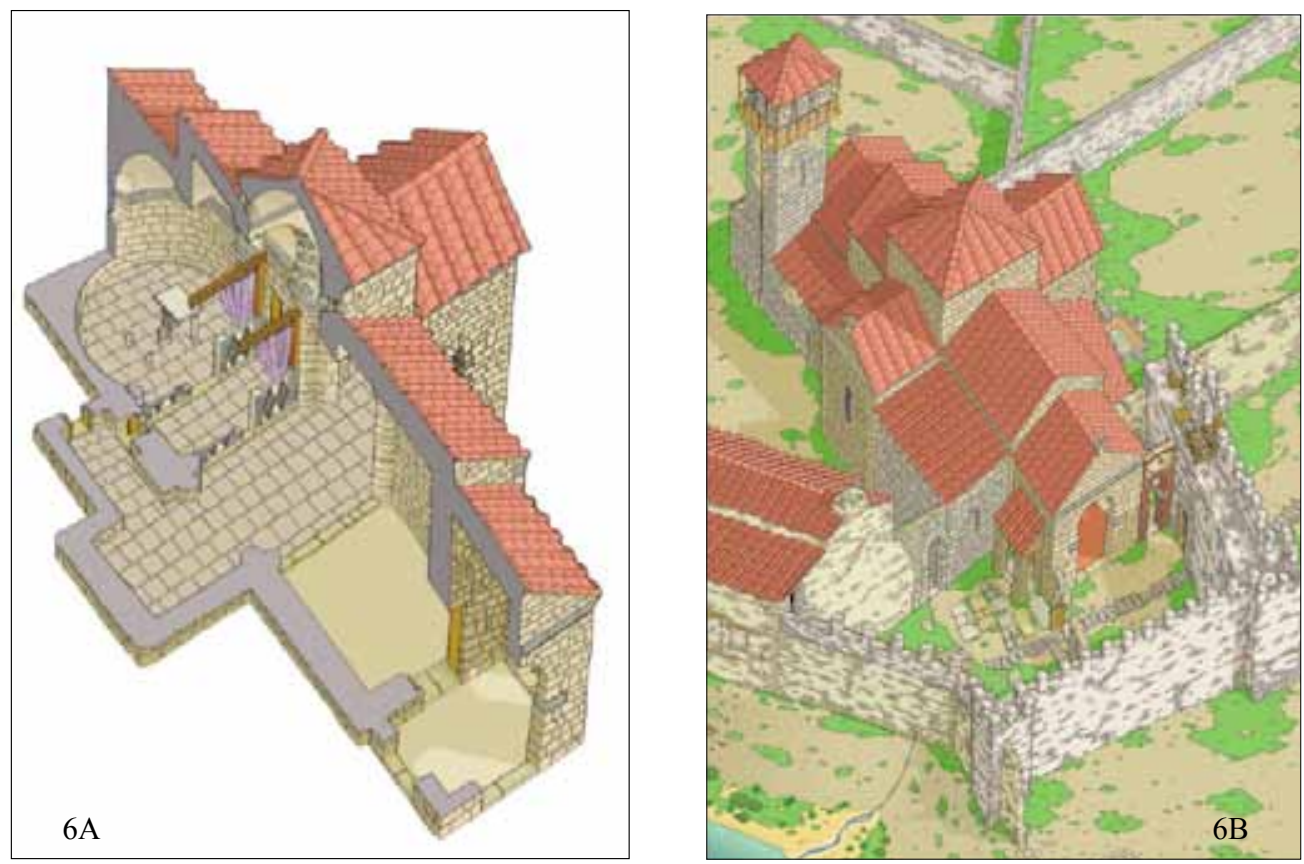

Fig. 6. 6A. El monasterio de Melque (San Martín de Montalbán, Toledo). La iglesia en su primera fase. $6 \mathrm{~B}$. El monasterio de Melque. Iglesia y su entorno que, tras sufrir un suceso violento, se fortificó y se emprendieron reformas litúrgicas que afectaron al edificio. [Dibujos de Fernando Sáez].

facilitado su estudio modular que es similar al conocido de las iglesias asturianas y del Duero ${ }^{28}$. El resultado cronológico replantea la cronología de las producciones

representación del abad, separado del anterior por una cerca y con el se comunicaba a través de la iglesia que actuaba de vestíbulo de acceso; y uno tercero de servicios. Es llamativa, sin que de ello deriven por hoy otras conclusiones, la similitud entre la situación topográfica de la iglesia en el conjunto residencial de Melque y el del "vestíbulo" en el palacio de Ammān (anterior a 749). A. ALMAGRO, P. JIMÉNEZ y J. NAVARRO, El palacio omeya de Àmmān. III. Investigación arqueológica y restauración. 1989-1997, Granada, 2000, fig. 2 y 5 . El suceso violento sufrido en Melque obligó a fortificar el monasterio con una muralla y a modificar la estructura de la iglesia. Se le añadió una capilla quizás con función martirial o relicario, se impidió la comunicación a través de ella y se realizó un profundo cambio litúrgico que dio lugar a la multiplicación de santuarios. F. J. MORENO MARTÍN, "Amenaza exterior y respuesta constructiva en el seno de una comunidad protegida. El caso de Santa María de Melque en el siglo IX”, en I. MONTEIRA, A. B. MUÑOZ y F. VILLASEÑOR (edits.), Relegados al margen. Marginalidad y espacios marginales en la cultura medieval, Madrid, 2009, pp. 41-53. L. CABALLERO y F. J. MORENO, op. cit; e.p. En El Trampal debió ocurrir algún proceso violento parecido.

28 L. ARIAS PÁRAMO, "Geometría, Metrología y Proporción en la Arquitectura alto medieval de la meseta del Duero", en L. CABALLERO, P. MATEOS y C. GARCÍA DE CASTRO (edits.) Asturias entre Visigodos y Mozárabes, Anejos de AEspA, 63, Madrid, 2012, pp. 353-390. Ambas iglesias estuvieron completamente abovedadas, decorada la de Melque con estucos y la del Trampal con frisos integrados en la arquitectura. 
arquitectónicas y escultóricas de ambos conjuntos que entra en contradicción con la propuesta dada por el modelo explicativo tradicional.

\begin{tabular}{|c|c|c|c|c|}
\hline Muestra & $\mathbf{A E}$ & Fase & Fecha A.D. & $\begin{array}{c}\text { Referencia } \\
\text { analítica }\end{array}$ \\
\hline \multirow[t]{2}{*}{ C-14 estuco iglesia } & \multirow[t]{2}{*}{240} & \multirow{10}{*}{ Ia } & 636-891 cal & UtC-3625 \\
\hline & & & $668-773 \mathrm{cal}$ & AA-33543 \\
\hline $\mathrm{C}-14$ & 243 & & $674-815 \mathrm{cal}$ & CSIC-1303 \\
\hline $\begin{array}{l}\text { Combinación de probabilidades } \\
\text { de las tres fechas anteriores }\end{array}$ & & & $(680-773 \mathrm{cal})$ & \\
\hline \multirow{6}{*}{$\mathrm{C}-14$} & $512 \mathrm{~A}$ & & $400-600 \mathrm{cal}$ & CSIC-1997 \\
\hline & 654 & & $540-670 \mathrm{cal}$ & CSIC-1998 \\
\hline & 489 & & $663-775 \mathrm{cal}$ & CSIC-1764 \\
\hline & $489 \mathrm{~A}$ & & $764-887 \mathrm{cal}$ & CSIC-1800 \\
\hline & $515 \mathrm{~A}$ & & $778-902 \mathrm{cal}$ & CSIC-1801 \\
\hline & $351 \mathrm{~A}$ & & $976-1042 \mathrm{cal}$ & CSIC-1742 \\
\hline \multirow[t]{2}{*}{ C-14 } & 687 & \multirow[t]{2}{*}{$\mathrm{Ib}$} & $580-690 \mathrm{cal}$ & CSIC-1999 \\
\hline & 238 & & 686-877 cal & CSIC-1202 \\
\hline \multirow{3}{*}{ C-14 } & 711 & \multirow{3}{*}{$\mathrm{Ib} / \mathrm{c}$} & $430-610 \mathrm{cal}$ & CSIC-2100 \\
\hline & 385 & & $721-890 \mathrm{cal}$ & CSIC-1701 \\
\hline & 386 & & $1155-1256 \mathrm{cal}$ & CSIC-1741 \\
\hline \multirow[t]{3}{*}{$\mathrm{C}-14$} & 517 & \multirow{7}{*}{ Ic } & $530-670 \mathrm{cal}$ & CSIC-2101 \\
\hline & 482 & & $663-775 \mathrm{cal}$ & CSIC-1765 \\
\hline & 236 & & $765-981 \mathrm{cal}$ & CSIC-1203 \\
\hline Cerámica Clara D H-105 & 236 & & 589/600-660/698 & \\
\hline Moneda Egica-Vitiza & 469 & & $695-702$ & \\
\hline \multirow{2}{*}{$\begin{array}{l}\text { Termoluminiscencia. Tejas } \\
\text { monasterio }\end{array}$} & \multirow[t]{2}{*}{383} & & $\begin{array}{l}755 \\
(1245 \pm 96 \text { B.P. })\end{array}$ & MAD-2347 \\
\hline & & & $\begin{array}{l}788 \\
(1212 \pm 97 \text { B.P.) }\end{array}$ & MAD-2341 \\
\hline
\end{tabular}

Cuadro 2. Iglesia y monasterio de Melque. Datos cronológicos “absolutos” en relación con las fases distinguidas por la excavación estratigráfica. AE, actividad estratigráfica o conjunto de unidades estratigráficas. Fases: Ia, construcción; Ib, uso, suelos; Ic, abandono, ruina.

La iglesia de San Juan de Baños (Baños de Cerrato, Palencia) se considera clave para el modelo explicativo visigotista. El año de 661, grabado en la inscripción de su dedicación por el rey Recesvinto, ha servido para datar su arquitectura y su decoración y consecuentemente como referencia inmutable para la fecha de otros edificios y grupos decorativos similares considerados por ello visigodos. Pero su lectura estratigráfica rompe este punto muerto historiográfico ${ }^{29}$. Por una parte descubre que no posee una sola decoración modelo, sino en realidad tres grupos distintos de escultura

29 L. CABALlERO y S. FEIJOO, "La iglesia altomedieval de San Juan Bautista en Baños de Cerrato (Palencia)", Archivo Español de Arqueología, 71 (1998), pp. 181-242. 


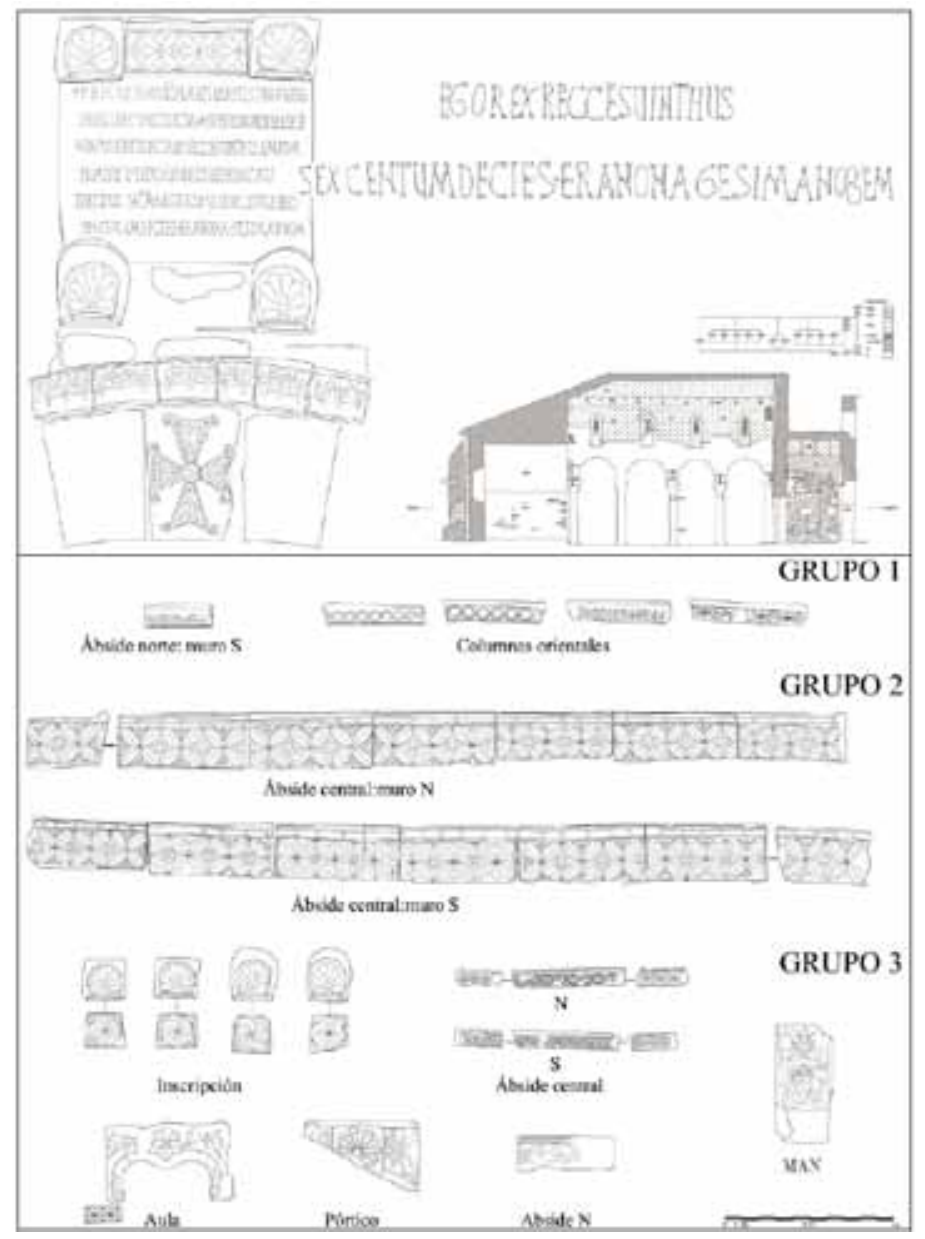

Fig. 7. San Juan Bautista de Baños de Cerrato (Palencia). La inscripción del rey Recesvinto, fechada en 661 d.C., y los tres grupos decorativos puestos en evidencia por el registro arqueológico. Los dos primeros son anteriores a la iglesia y reutilizados en su fábrica. Sólo el tercer se realizó ex profeso para ella y en consecuencia data su construcción

[L. CABALLERO y S. FEIJOO, "La iglesia altomedieval de San Juan Bautista en Baños de Cerrato (Palencia)", Archivo Español de Arqueología, 71 (1998)].

decorativa. De ellos, sólo el tercero está formado por materiales tallados específicamente para la iglesia, mientras que los de los otros dos son reutilizados. Algunos motivos del grupo elaborado a propósito para la iglesia se relacionan con otros propios de la escultura del s. IX asturiana (fig. 7). Por otra parte, la lectura estratigráfica diferencia los restos del edificio originario, las reconstrucciones medievales, especialmente la gótica, y las restauraciones modernas, y de este modo permite presentar la forma del edificio originario. Por lo tanto, los resultados contradicen el modelo 


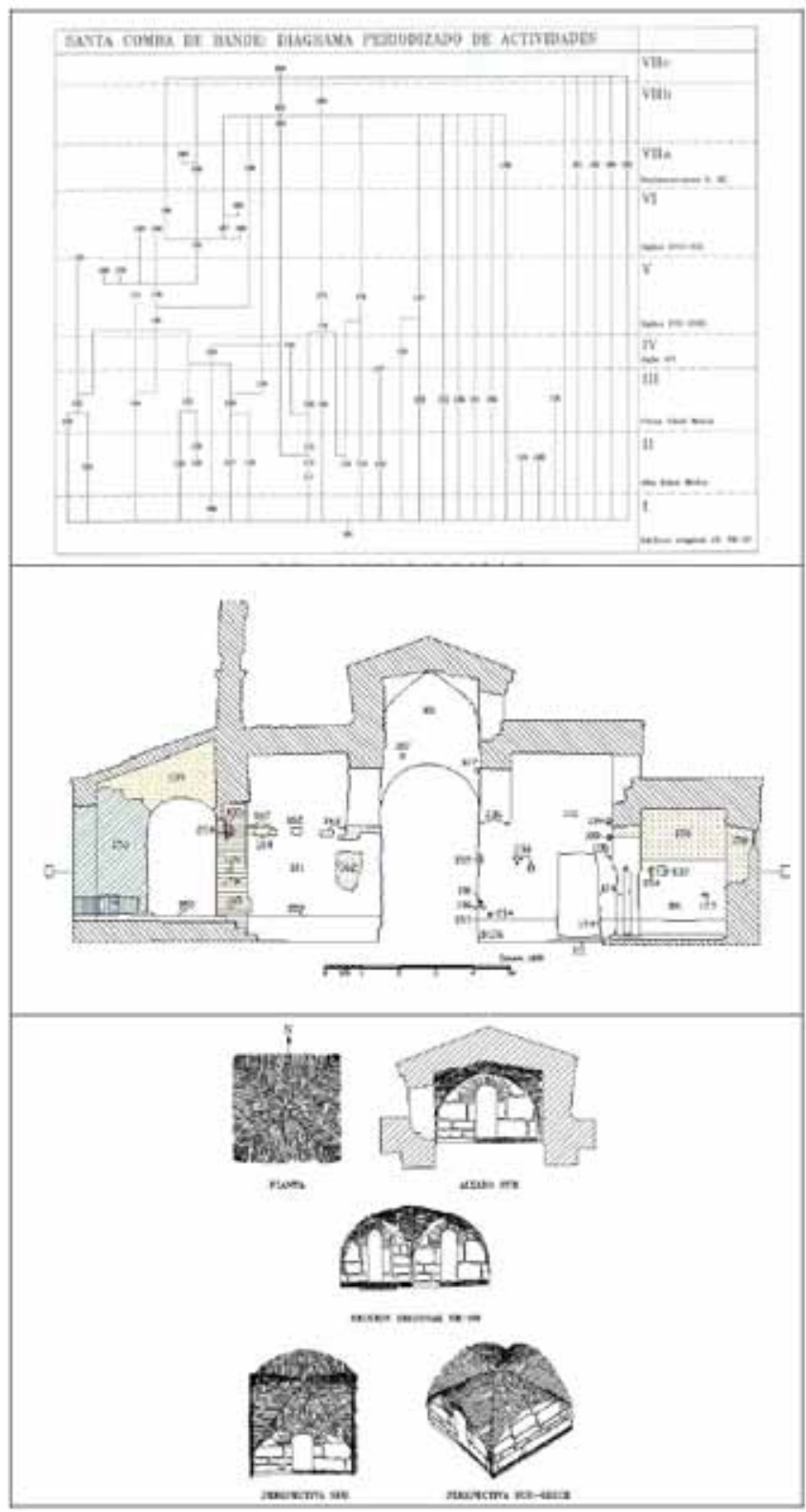

Fig. 8. Santa Comba de Bande (Orense). Su registro arqueológico evidencia la conservación casi completa del edificio originario y, por lo tanto, contradice la restauración evidenciada por las fuentes escritas. La bóveda de ladrillo la relaciona con ciertos edificios de su zona y considerados "mozárabes" [L. CABALLERO, F. ARCE y M. Á. UTRERO, "La iglesia de San Torcuato de Santa Comba de Bande (Orense): Arqueología de la Arquitectura", Archivo Español de Arqueología, 77 (2004)]. 
visigotista, planteando la duda de si la inscripción pertenece al edificio originario o si es uno más de los materiales reutilizados. Recientemente se ha propuesto su datación altomedieval como consecuencia de su estudio epigráfico ${ }^{30}$.

Algo similar ocurre con la iglesia de Santa Comba de Bande (Orense) considerada también pieza clave de la explicación visigotista. Un documento altomedieval data su construcción doscientos o más años antes de que fuera repoblada en el año 982, etapa durante la cual habría estado abandonada. Por ello se ha intentado justificar la existencia en su arquitectura de dos etapas correspondientes a las del documento ${ }^{31}$. La lectura estratigráfica demuestra la existencia de una sola etapa y el mantenimiento continuado de la fábrica que impide suponer la existencia de dos siglos de abandono $^{32}$. Además, las características de una pareja de sus capiteles y de las bóvedas de ladrillo se refieren a producciones altomedievales (fig. 8). Es evidente que la estructura del documento medieval falsea los datos a favor de sus intereses. La lectura estratigráfica provoca la disociación entre edificio y documento y obliga a datar el primero por sus caracteres en época altomedieval.

Otro edificio modélico para la explicación visigotista es la iglesia de San Pedro de la Nave (Zamora) que fue trasladada de lugar en el año 1930 por la construcción de un embalse que iba a anegar su solar. Ello planteaba el problema de si su registro arqueológico podía dar un resultado plausible ${ }^{33}$. Sin embargo el rigor del traslado y la virtualidad del método han permitido recuperar la secuencia de su historia, diferenciando los elementos pertenecientes a su etapa originaria y facilitando la reconstrucción de su forma (fig. 9). Durante el traslado se descubrieron piezas decorativas reutilizadas en el edificio que podían pertenecer a un grupo decorativo anterior a la construcción del edificio y que se explicaron como que la iglesia se había construido en dos etapas de obra ${ }^{34}$. Pero la lectura confirma la unidad entre edificio y escultura decorativa. Las piezas reutilizadas pertenecen al mismo taller que, por causas que desconocemos (quizás, entre otras, por un cambio de programa iconográfico), aprovechó parte de su producción. Por otra parte, la decoración está elaborada por dos manos o maestros distintos, pero coetáneos y pertenecientes al mismo taller. La posterior excavación arqueológica de parte de su yacimiento confirma y completa su planta con un anejo occidental y un posible baptisterio de tipología altomedieval ${ }^{35}$.

30 J. del HOYO, “A propósito de la inscripción dedicatoria de San Juan de Baños”, en C. FERNÁNDEZ MARTÍNEZ y J. GÓMEZ PALLARÉS (edits.), Temptanda Viast. Nuevos estudios sobre la poesía epigráfica latina, SPUAB, CDROM, 18, Bellaterra, 2006, 22 páginas.

31 L. CABALLERO y J. I. LATORRE, op. cit; 1980. P. de PALOL, Arte hispánico de la época visigoda, Barcelona, 1968.

32 L. CABALlero, F. ARCE y M. Á. UTRERO, "La iglesia de San Torcuato de Santa Comba de Bande (Orense): Arqueología de la Arquitectura”, Archivo Español de Arqueología, 77 (2004), pp. 273-318.

33 L. CABALLERO ZOREDA (coord.), La iglesia de San Pedro de La Nave, Zamora, Instituto de Estudios Zamoranos Florián de Ocampo, 2004.

34 M. GÓMEZ-MORENO, op. cit; 1966. R. CORZO, San Pedro de La Nave. Estudio histórico y arqueológico de la iglesia visigoda, Zamora, Instituto de Estudios Zamoranos Florián de Ocampo, 1986.

35 Antes me referí a la explicación dada por H. Schlunk a sus escenas decorativas que suponía coetáneas a una miniatura desconocida de época visigoda. La explicación visigotista no toma en consideración, posiblemente porque la contraría, la donación de tierras al monasterio de San Pedro de Tunis por el rey Alfonso III documentada en 907, trece años después de la conquista de la ciudad de Zamora. 


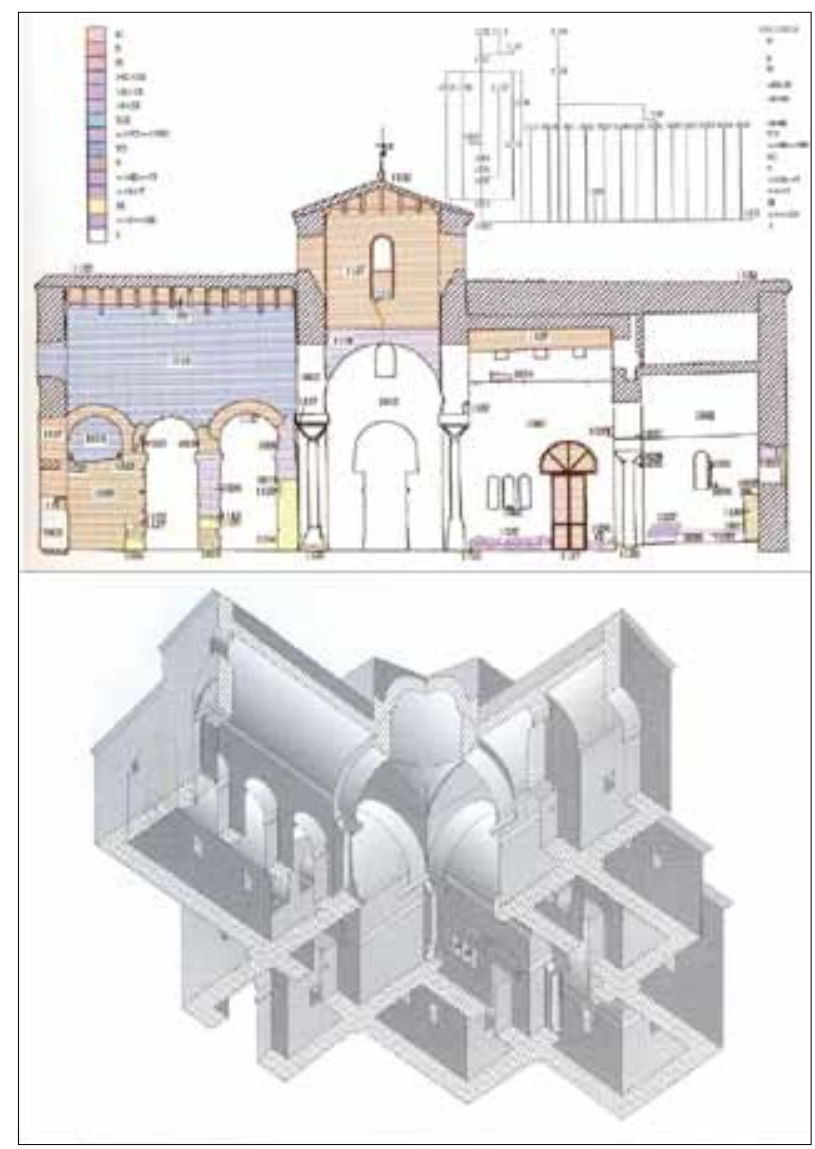

Fig. 9. San Pedro de La Nave (Zamora). En lo que se conserva del edificio anterior a su primera ruina, no es posible distinguir dos etapas. El registro arqueológico permite efectuar una propuesta de restauración de su forma originaria [L. CABALLERO ZOREDA (coord.), La iglesia de San Pedro de La Nave, Zamora, Instituto de Estudios Zamoranos Florián de Ocampo, 2004].

La llamada Sé de Idanha-a-Velha (Portugal) es un edificio basilical con dos curiosas características, su dirección norte-sur y presentar un ábside transversal orientado a este. Por lo tanto no encaja ni con el modelo de basílica cristiana, pues debería orientar su aula igual que el ábside o santuario, ni con el de mezquita que debería orientar el edificio, según la tradición andalusí, hacia el sur y a la que le faltaría el patio preceptivo. La interpretación como basílica cristiana no tiene en cuenta sus singularidades. Otras explicaciones son sincréticas entre las posibilidades cristiana y musulmana; serviría para cristianos o musulmanes, muladíes en realidad influidos cada uno por la religión contraria, lo que explicaría las diferencias arquitectónicas. 


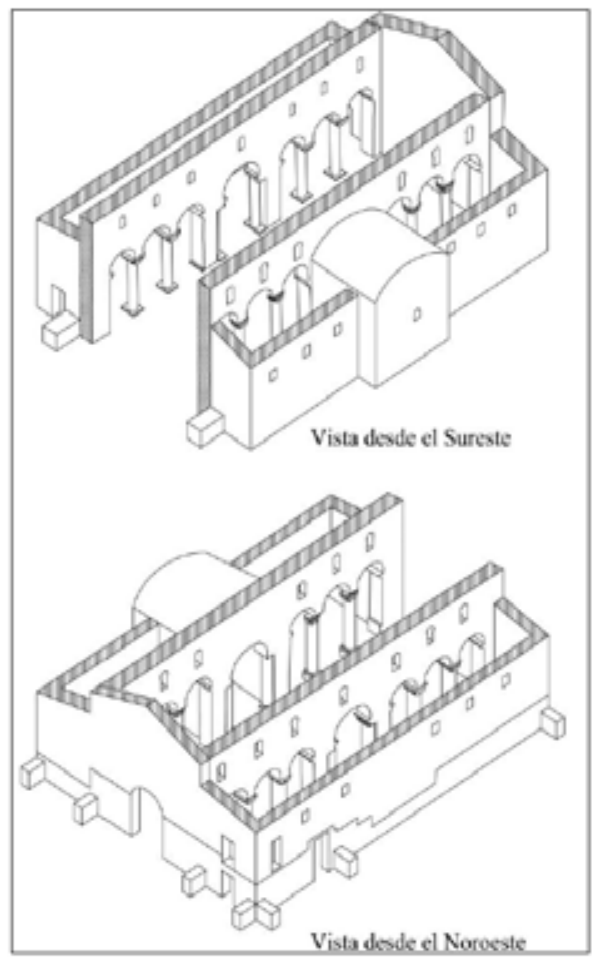

Fig. 10. Sé de Idanha-a-Velha (Castelo Branco, Portugal). La lectura del edificio descubre que no es lógico que sea ni una iglesia ni una mezquita dadas sus habitaciones adosadas que impedían la existencia del patio y desde las que se accedía a ella por puertas altas [L. CABALLERO ZOREDA, "Aportaciones de la lectura de paramentos a la polémica sobre la Sé de Idanha-a-Velha”, Al-Ândalus. Espaço de mudanza. Balanço de 25 años de história e arqueologia medievais. Seminario Internacional, Homenagem a Juan Zozaya Stabel-Hansen (Maio 2005), Mértola, 2006].

La lectura estratigráfica concluye que se trata de un edificio unitario ${ }^{36}$. Las diferencias de aparejo (sillería para la zona inferior de los muros y arquerías y mampostería para el desarrollo en altura) y de la forma del ábside (situado transversalmente) no significan varias etapas en el edificio. Pero a la vez distingue otras características, evidentes pero que, como hemos visto en otros casos, un análisis menos metódico del edificio pasa por alto. El edificio forma parte de un conjunto mayor con otras habitaciones desaparecidas de las que sólo restan los enjarjes de las zonas inferiores de sillería; y, a los lados de su esquina noroeste, posee dos puertas altas que se deben considerar accesos desde las habitaciones vecinas desaparecidas (fig. 10). A pesar de

36 L. CABALLERO ZOREDA, “Aportaciones de la lectura de paramentos a la polémica sobre la Sé de Idanha-a-Velha”, Al-Ândalus. Espaço de mudanza. Balanço de 25 años de história e arqueologia medievais. Seminario Internacional, Homenagem a Juan Zozaya Stabel-Hansen (Maio 2005), Mértola, 2006, pp. 266273. 
sus paralelos formales con las mezquitas de Bosra o Qasr al-Hayr al Sharqi (Siria), no puede considerarse una mezquita. La lectura de paramentos obliga a pensar en otra explicación, que falta por desarrollar, quizás un palacio ${ }^{37}$.

La estrategia estratigráfica, que distingue estratos, se debe compaginar con la estrategia tipológica, que distingue los fósiles o tipos que corresponden a cada estrato. $\mathrm{Su}$ uso combinado da lugar a tipologías, ordenadas secuencialmente y convertidas en una herramienta de la llamada "cronología absoluta". Estas tipologías permiten datar a su vez otros elementos aislados del conjunto que sirve de referencia.

Como antes he dicho, uno de los puntos de arranque del nuevo modelo explicativo fue la constatación de contradicciones en el modelo tradicional visigotista. Una de estas contradicciones la plantea un amplio grupo de iglesias que se extienden por las provincias de Álava, La Rioja y Burgos. Sus tipos son similares, basilicales de una o tres naves cubiertas de armadura y con la presencia como elemento diferenciador de bóvedas baídas sobre pechinas, construidas con piedra toba, cubriendo sus ábsides. Dos de sus ejemplares se habían datado antes de la fecha de referencia del 711, Quintanilla de las Viñas y Ventas Blancas, pero los demás se consideraban posteriores al 711.

El estudio arqueológico que realizó Azkarate de una de estas iglesias, la de San Román de Tobillas (Álava), demostró una compleja secuencia estratigráfica ${ }^{38}$. Su comparación con datos documentales y epigráficos aseguraba la construcción del edificio originario poco antes del año 822 por el abad Avito y una segunda fase de reforma prerrománica en el 939 (fig. 11).

Por estas y otras razones propuse considerar el grupo homogéneo y de época altomedieval, documentando buena parte de ellos y estudiando arqueológicamente las iglesias de San Pedro el Viejo de Arlanza y San Vicente del Valle, también con varias etapas altomedievales ${ }^{39}$. A ellos se unen aun otros edificios, como Tabladillo, Santa Coloma, Santa María de los Arcos de Tricio, San Felices de Oca y Santa Cecilia de Barriosuso.

A partir de la experiencia de Tobillas, Sánchez Zufiaurre desarrolló un novedoso estudio de la arquitectura prerrománica en la provincia de Álava donde de hecho se desconocía la existencia de este tipo de arquitectura ${ }^{40}$. Utilizó para ello ambas estrategias estratigráfica y tipológica. Las citas documentales le permitieron efectuar

37 P. ALMEIDA FERNANDES, "Antes e depois da Arqueología da Arquitectura: um novo ciclo na investigação da mesquita-catedral de Idanha-a-Velha”, Artis, 5 (2006), pp. 49-72.

38 A. AZKARATE GARAI-OLAUN, "Aportaciones al debate sobre la arquitectura prerrománica peninsular: la iglesia de San Román de Tobillas (Álava)”, Archivo Español de Arqueología, 68 (1995), pp. 189-214.

39 L. CABALLERO et alii, "La iglesia prerrománica de S. Pedro el Viejo de Arlanza (Hortigüela, Burgos)", Numantia, 5 (1991-92), pp. 139-165. F. ARCE SAINZ, "La iglesia alto medieval de la Asunción en San Vicente del Valle (Burgos): historiografía, estratigrafía e interpretación”, Arqueología de la Arquitectura, 7 (2010), pp. 67-103.

40 L. SÁNCHEZ ZUFIAURRE, Técnicas constructivas medievales. Nuevos documentos arqueológicos para el estudio de la Alta Edad Media en Álava, EKOB, 3. Universidad del País Vasco, Vitoria, 2007. 


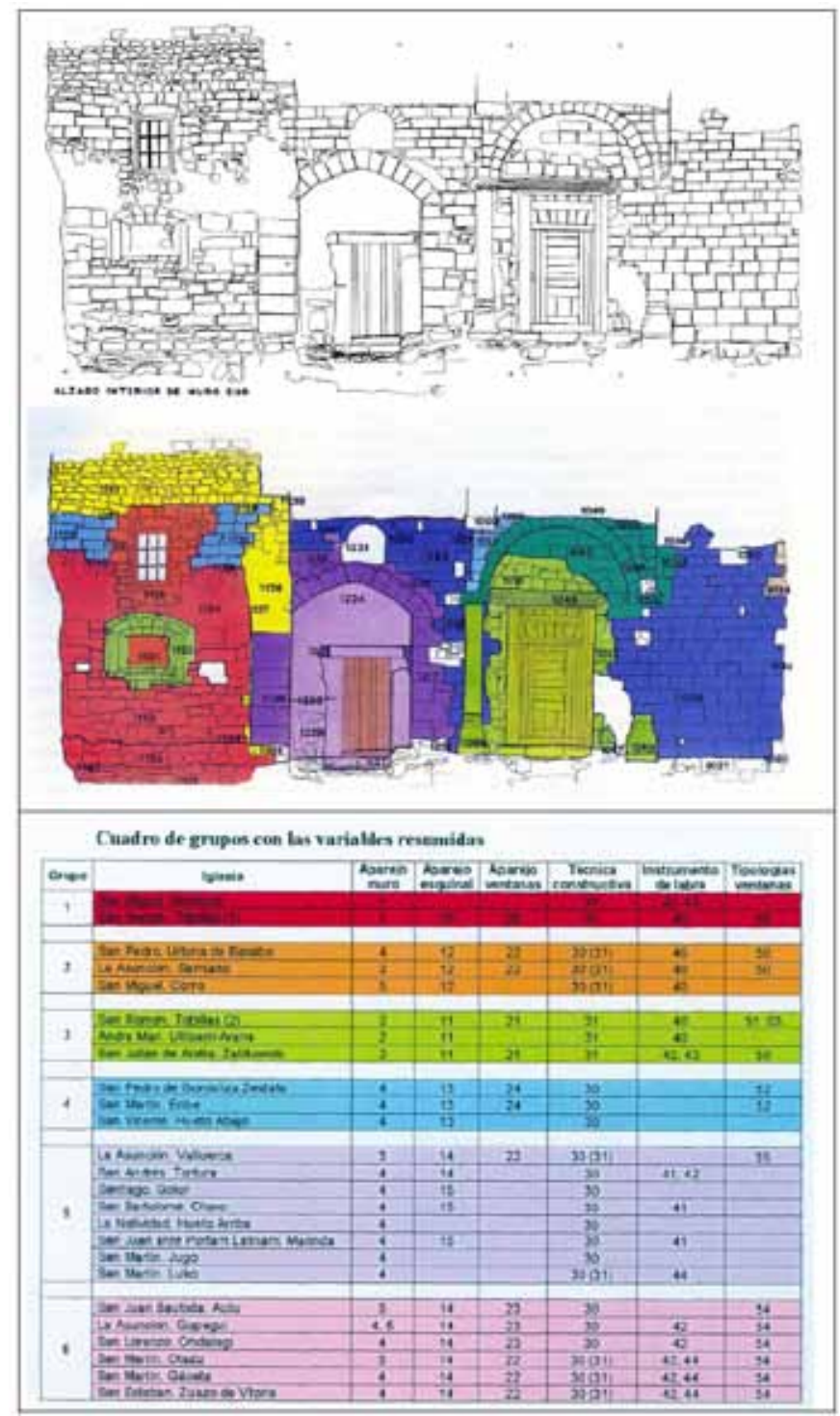

Fig. 11. La iglesia de Tobillas (Álava) pertenece a un grupo de iglesias situadas en las provincias de Burgos, La Rioja y Álava (primera fase inmediata a 822 y segunda en 939 d.C.). Su estudio indujo la búsqueda de otras iglesias "prerrománicas" en esta provincia mediante un estudio tipológico de sus "variables" técnicas [A. AZKARATE GARAI-OLAUN, “Aportaciones al debate sobre la arquitectura prerrománica peninsular: la iglesia de San Román de Tobillas (Álava)", Archivo Español de Arqueología, 68 (1995), pp. 189-214 y L. SÁNCHEZ ZUFIAURRE, Técnicas constructivas medievales. Nuevos documentos arqueológicos para el estudio de la Alta Edad Media en Álava, EKOB, 3. Universidad del País Vasco, Vitoria, 2007]. 
primero un mapa de distribución de cerca de 400 iglesias alavesas anteriores a época románica y aún en funcionamiento. Efectuadas una prospección meticulosa y un estudio estratigráfico básico de estas iglesias, distinguió veinticinco de ellas que aún conservan restos de construcciones anteriores a época románica. Diferenció y estudió sus variables o caracteres tipológicos, agrupando los edificios de acuerdo a ellas y distinguiendo y definiendo de este modo seis grupos (fig. 11). Los datos documentales y los cruces de características técnicas le permitieron datar estos grupos entre los siglos IX y XII. De este modo, en un territorio donde se desconocían hasta ese momento iglesias prerrománicas, no sólo se descubría su existencia numerosa, sino que se ordenaban cronológicamente en seis grupos distintos. Ahora Sánchez Zufiaurre podía comparar estas iglesias con las del grupo diferenciado antes en La Rioja y Burgos, relacionando la mayoría de ellas con uno de sus grupos alaveses, el número 1 que incluía la primera etapa de Tobillas (s. IX), discriminadas por la utilización de sillería reutilizada. Pero no todas las iglesias del grupo burgalés-riojano se incluyen en este grupo; otras se encuadran en otros grupos por la presencia bien de sillería ex novo o por la presencia de mampostería.

\section{$* * *$}

Llamamos registro "configuracional" a la lectura secuencial de un edificio en el que, por la contemporaneidad de sus partes o por encontrarse estas cubiertas por enfoscados, no es posible diferenciar estratos ${ }^{41}$. Se trata de intentar un registro arqueológico sin estratos o con ellos ocultos.

La iglesia "asturiana" de San Miguel de Lillo (Oviedo, Asturias) conserva en el momento actual sólo la parte trasera de su edificio antiguo, formado por un tramo con una tribuna y sus escaleras de acceso y otro tramo que aparenta un crucero elevado de tres tramos. El registro sistematiza dos observaciones principales que no son propiamente estratigráficas. Primero, la existencia de abundantes piezas singulares que están reutilizadas en el edificio como demuestran sus recortes y retalles y sus posiciones forzadas, viradas o en lugares para las que no fueron creadas. Segundo, dos grupos decorativos diferenciados por su material, motivos y técnica de talla. Tanto las piezas del primer grupo reutilizadas como las del segundo aparecen en el tramo de la tribuna, mientras que las piezas del primer grupo no reutilizadas se conservan en las columnas que cierran la falsa cabecera de la actual iglesia. La forma de una de las basas reutilizadas indica que debía colocarse originalmente en un rincón, ya que sólo presenta decoración en dos caras ${ }^{42}$. De todos estos indicios, a pesar de que no exista una estratigrafía que lo evidencie, quizás por tratarse de obras coetáneas, se puede deducir que durante la construcción de la iglesia y sobre la marcha se decidió la reforma de su proyecto incluyendo al fondo de una iglesia basilical el cuerpo elevado de una tribuna. Para el cambio de proyecto se mantuvo el equipo de albañilería mientras que se sustituyó el equipo de decoradores porque debían ser ellos los que

41 T. MANNONI, "Metodi di datazione dell'edilizia storica", Archeologia Medievale, 11 (1984), pp. 396403.

42 L. CABALLERO et alii, La iglesia de San Miguel de Lillo (Asturias). Lectura de paramentos 2006, Anejos de Territorio, Sociedad y Poder, 1, Oviedo, 2008. 

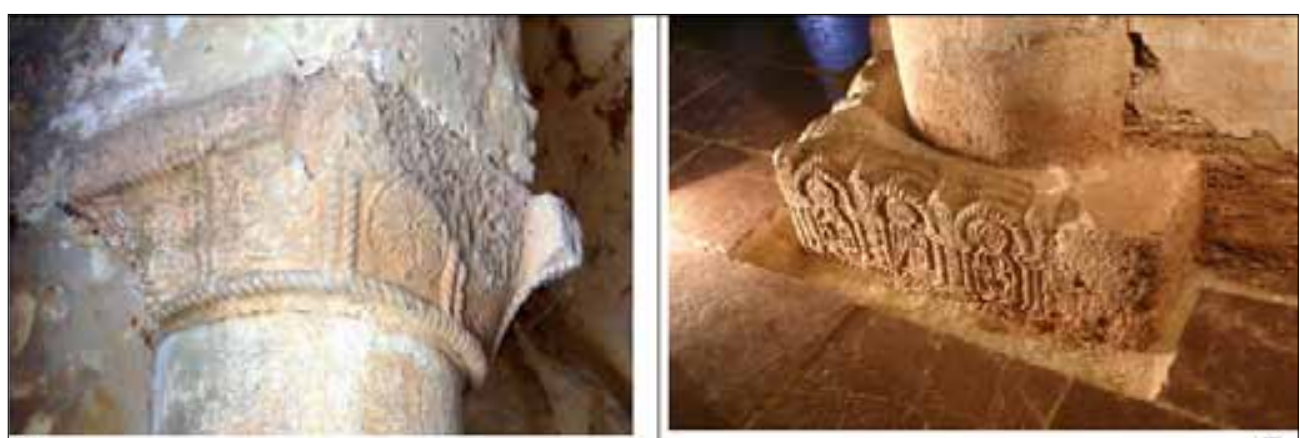

$1 \mathrm{~A}$
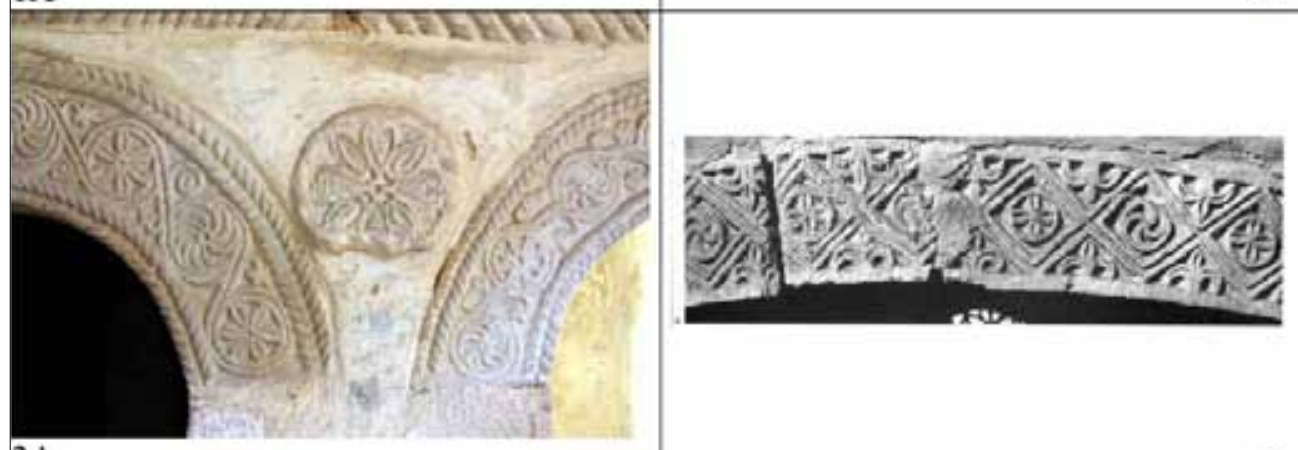

$2 \mathrm{~A}$

Fig. 12. El análisis "configuracional" de la iglesia de San Miguel de Lillo (Oviedo) permitió distinguir la reforma efectuada sobre la marcha en ella para incluir el cuerpo de la tribuna trasera. Tanto el proyecto originario como el de reforma tuvieron su propio taller decorativo. El segundo aprovechó del primero su mano de obra (obligándole a cambiar sus cartones) y sus piezas (que removió de lugar) [L. CABALLERO et alii, La iglesia de San Miguel de Lillo (Asturias). Lectura de paramentos 2006, Anejos de Territorio, Sociedad y Poder, 1, Oviedo, 2008].

llevaban la dirección de la obra (fig. 12). La iglesia se debió arruinar probablemente en un corto espacio de tiempo pero fue la parte reformada la que mejor resistió, quizás por su estructura reforzada de arcos y bóvedas superpuestas, desapareciendo por completo la estructura que supongo basilical. Bien la inclusión de la tribuna o bien su inmediata ruina obligaron al cierre de las naves laterales, con restos de piezas decorativas y coetáneo a la decoración pintada de la iglesia. Por una de estas razones tampoco se observan soluciones de continuidad o adosamientos que justifiquen estratigráficamente esta tercera etapa.

La iglesia asturiana de Santianes de Pravia se data tradicionalmente por una inscripción, hoy fragmentada, que decía en forma laberíntica: SILO PRINCEPS FECIT, que se supone que se refiere a la iglesia y que, por lo tanto, se considera construida hacia el año 775. El estado actual de la iglesia se debe a la restauración efectuada por el arquitecto José Menéndez-Pidal quien pretendía haber restaurado su forma 


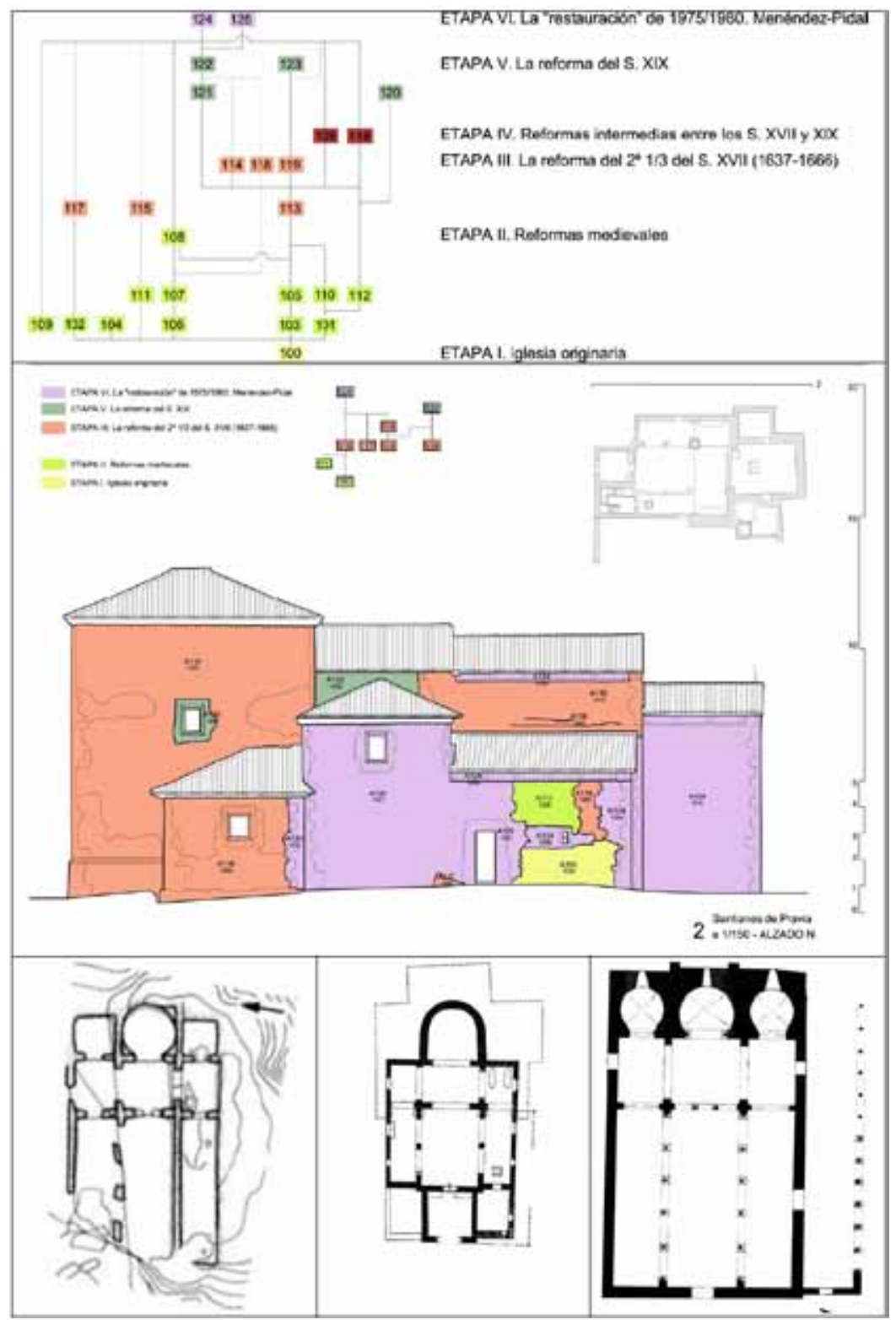

Fig. 13. Santianes de Pravia (Asturias). El registro arqueológico demuestra que, aunque se conservan suficientes indicios de su planta originaria, apenas quedan restos de su alzado primitivo. A pesar de ello, por su planta y organización litúrgica se puede asegurar que se asimila al grupo de iglesias con transepto tripartito "mozárabe", contradiciendo la autoridad otorgada al epígrafe de Silo por el que se databa en la segunda mitad del s. VIII. Plantas de las iglesias de Bobastro (Málaga), Pravia y Escalada (León). 
original. Se trataba pues de confirmar esta supuesta recuperación; los restos antiguos que se conservaban; y si se podían datar en el s. VIII. La secuencia narra su martirizada historia. En el s. XVII sufrió la transformación del ábside, naves y pórtico y el desmonte de sus elementos litúrgicos. Ello dio lugar a un pleito de los vecinos pidiendo amparo al rey frente al párroco, enojados por la transformación de la iglesia; pleito en el que aparecen datos interesantes sobre la forma anterior de la iglesia y su organización litúrgica con canceles e iconostasio. Tras nuevas reformas del crucero en el s. XIX, en los años 1975-1980, el arquitecto Menéndez-Pidal, para recuperar supuestamente la forma del edificio original, la desmontó y rehizo, incluyendo una tribuna que nunca existió. Originario sólo se pudo descubrir una pequeña parte del muro norte y la planta de la iglesia, confirmada por los restos conservados del suelo de hormigón hidráulico (fig. 13). Es milagroso que en su estructura real aún se pueda observar algo del edificio inicial ${ }^{43}$. Sin embargo lo registrado da lugar a observaciones significativas.

La conservada planta de la iglesia entra en contradicción con la fecha que se considera de su construcción por Silo. Se trata de una iglesia basilical con transepto de tres tramos, canceles y el posible iconostasio. Las referencias para características similares se concentran hacia el año 900 o sea más de un siglo después. Cabe preguntarse hasta qué punto la iglesia encaja en la denominación "mozárabe" o "asturiana", confirmando el relativo valor que de hecho tienen estas y otras denominaciones similares (fig. 13). Lo anterior también pone en entredicho la información de la inscripción laberíntica. De la iglesia proceden tres inscripciones antiguas. Dos de ellas, una fundacional y otra honorífica, presentan caracteres similares que no son contradictorios con la cultura epigráfica asturiana de los siglos IX e inicios del X. Pero la inscripción fundacional ha sufrido una damnatio memoriae y desconocemos quién constaba como promotor. Al contrario, la tercera inscripción de Silo es anómala. Su epigrafía no conviene con las anteriores; su forma laberíntica debe adelantarse a fines del s. X, al menos; y su reconstruida historia la sitúa en Oviedo hasta su traslado a Santianes a fines del s. XVI ${ }^{44}$. Como ya vimos en Baños, la epigrafía no es fiable si no se contextualiza con rigor previamente.

\section{$* * *$}

A pesar de la utilización que he hecho del estudio de la decoración arquitectónica como apoyo para defender mi modelo explicativo, no se puede afirmar que haya desarrollado una estrategia de tipología decorativa. En realidad son los datos aportados por la estrategia estratigráfica sobre la escultura decorativa la que me ha permitido una explicación distinta de su desarrollo altomedieval. Resumo los datos conseguidos y en parte ya citados.

43 L. CABALLERO y J. I. MURILLO, "San Juan Evangelista de Santianes de Pravia. La obra del rey Silo, una supuesta iglesia construida y decorada hacia el año 900", Las iglesias asturianas de Pravia y Tuñón. Arqueología de la Arquitectura, en L. CABALLERO y E. RODRÍGUEZ (edits.), Anejos de AEspA 54, Madrid, 2010, pp. 11-90.

44 H. GIMENO y J. del HOYO, "La epigrafía medieval asturiana. Los epígrafes de la iglesia de San Juan de Santianes de Pravia”, en L. CABALLERO, P. MATEOS y C. GARCÍA DE CASTRO (edits.), op. cit; 2012, pp. 13-26. 
En Mérida después del 711 se adoptaron nuevos temas decorativos de procedencia omeya y nuevos usos arquitectónicos como los frisos de impostas decoradas, plausiblemente por la llegada de técnicos orientales ${ }^{45}$. Estas reformas se produjeron manteniendo la estructura previa del taller decorativo así como el tipo de piezas litúrgicas tradicionales, canceles, y su posición en la iglesia. Pertenecen a este taller del s. VIII los conjuntos de Santa Eulalia de Mérida y El Trampal. En Toledo debió producirse un hecho similar como demuestra la parecida decoración de Melque ${ }^{46}$.

Indicio de la misma llegada de técnicos omeyas con sus repertorios son, a mi parecer, los estucos y uno de los grupos de mosaicos de Villajoyosa (Alicante), que se pretenden de plena cronología romana, lo que creo imposible por su semejanza con los de Jirbat al Mafyar (Jordania) de quien creo que dependen y que explico por la reutilización de una villa romana para vivienda omeya ${ }^{47}$. Los motivos de sus estucos van a tener una amplia repercusión tanto en el taller ya citado de Mérida, como en el probablemente islámico de Lisboa, con producción en su catedral y castillo, en el monasterio de Chelas y en Alfanje (Santarém) y de cronología discutida entre los siglos VIII y $\mathrm{X}^{48}$.

Un tema procedente del palacio jordano, que denomino seudo roleo por su trazado geométrico, es indicio de los mecanismos de transferencia. Los prototipos del s. VIII (Jirbat al Mafyar y Villajoyosa) se reflejan en un grupo intermedio (Lillo y Pravia) que mantienen sus rasgos característicos en el s. IX e inicios del X. Esta semejanza fue la que me hizo mantener en un principio la cronología tradicional de Pravia. El adelanto ahora propuesto hacia 900 indica la dificultad de datar los talleres y su vitalidad que les hace mezclar sus variantes sin someterse a una evolución estrictamente lineal. A un grupo más avanzado, pero no por ello de cronología más moderna, pertenecerían las producciones de Lena y La Nave donde los roleos se reducen a series de círculos, casi perdidas las líneas de unión. Estos talleres presentan otros motivos que se encuentran también en el repertorio omeya y rasgos en los temas figurados (La Nave) y en el trazado de las figuras (Lillo) que enlazan con la coetánea miniatura mozárabe ${ }^{49}$.

El dinamismo del segundo taller de Lillo se demuestra por su presencia en el palacio de Oviedo y su estrecha relación con las producciones de Braga (Portugal), en

\footnotetext{
45 La presencia de nuevos temas decorativos ya fue señalado por M. CRUZ VILLALÓN, Mérida visigoda. La escultura arquitectónica y litúrgica, Badajoz, 1985.

46 P. MATEOS, op. cit; 1999. L. CABALLERO y F. SÁEZ, op. cit; 2009. L. CABALLERO ZOREDA, "La arquitectura denominada de época visigoda, ¿es realmente tardorromana o prerrománica", en L. CABALLERO y P. MATEOS (edits.), op. cit; 2000, pp. 207-247.

47 Ibídem. La opinión contraria en S. GUTIÉRREZ LLORET, "Algunas consideraciones sobre la cultura material de las épocas visigoda y emiral en el territorio de Tudmīr", en L. CABALLERO y P. MATEOS (edits.), op. cit; 2000, pp. 95-116.

48 R.W. HAMILTON, Khirbet al Mafjar: An Arabian Mansión in the Jordan Valley, Oxford, 1950. M.L. REAL, "Portugal: cultura visigoda e cultura moçárabe", en L. CABALLERO y P. MATEOS (edits.), op. cit; 2000, pp. 21-76.

49 L. CABALLERO ZOREDA, "Observaciones arqueológicas sobre producción arquitectónica y decorativa de las iglesias de S. Miguel de Lillo y Santianes de Pravia”, en L. CABALLERO, P. MATEOS y C. GARCÍA DE CASTRO (edits.), op. cit; 2012, pp. 89-124.
} 
Guimarães y São Frutuoso de Montelios, ésta otra de las iglesias supuesta visigoda pero que debe datarse en el s. IX por su coetánea producción ovetense ${ }^{50}$.

Recuerdo además las citas ya hechas a los estucos de Melque, con relaciones omeyas; los tres grupos decorativos de Baños, dos de ellos reutilizados y uno con referencias que considero asturianas; las dos manos del taller de La Nave y la reutilización de piezas de su propia producción, quizás forzada por una adecuación iconográfica; los dos talleres de Lillo, estrechamente relacionados con la producción arquitectónica e influenciados entre sí y un tercero, que quizás corresponde a la reforma debida a la ruina del edificio y que también trabaja en Tuñón. Son pues abundantes los datos que se refieren a la definición de talleres, en ocasiones a su expansión, al tránsito de sus motivos, a sus técnicas de producción y de reutilización de materiales. En resumen, a la producción y a la transferencia de las decoraciones.

$$
* * *
$$

La estratigrafía ofrece abundantes dataciones relativas pero adolece de dataciones absolutas $^{51}$. Se espera que estas las ofrezca la estrategia tipológica, siempre más dificultosa y lenta de construir, aunque no imposible como hemos visto con el ejemplo de las iglesias alavesas. Por ello he procurado potenciar una estrategia "dendrocronológica" como medio de obtener dataciones absolutas. Sin embargo la datación conseguida por sus análisis es contraria a mi propuesta ${ }^{52}$. El proceso de convertir las curvas "dendrocrológicas" flotantes de los escasos elementos que pueden analizarse en fechas absolutas de corte de los árboles es largo y complejo, pasando por la comparación de curvas, dataciones de carbono 14 y añadidos de tiempos que equivalgan a los tramos perdidos en las curvas por la talla de las maderas. Las vigas de las iglesias de Baños, La Nave, Quintanilla de las Viñas y Barriosuso se datan, con el mayor margen posible, entre los siglos VI y VIII, y las grapas de la sillería de La Nave en la segunda mitad del s. VII, esto es, en época visigoda. Esta estrategia presenta además la llamada "conexión Pino-Duero", peculiaridad que relaciona tan estrechamente los caracteres de las maderas de La Nave y Baños que supone deben proceder de una misma masa forestal, a pesar de la lejanía de los edificios entre sí y de sus diferencias técnicas y estructurales.

Esta contradicción enfrenta el paradigma que defiendo al talón de Aquiles de una posible refutación. Los estudios efectuados hasta ahora dentro de mi campo científico conforman una explicación global consistente. No se trata únicamente del planteamiento de una hipótesis, ni de la aplicación de una metodología novedosa, ni siquiera de la presentación sistemática de estudios monográficos. El momento de datar los edificios ya se ha rebasado una vez que se demuestra que la fecha considerada del

\footnotetext{
50 Ibídem.

51 Disiento de la tradicional denominación de cronologías absoluta y relativa. En nuestro ámbito de trabajo lo que es fundamental y previo para otorgar validez de indicio cronológico es la contextualización.

52 E. RODRÍGUEZ TROBAJO, "Procedencia y uso de madera de pino silvestre y pino laricio en edificios históricos de Castilla y Andalucía", Arqueología de la Arquitectura, 5 (2008), pp. 33-54. La estrategia "dendroconológica" para esta arquitectura se inició en 1995 con el apoyo de F. Alonso Mathías del Instituto Rocasolano, CSIC.
} 
siglo VII es una incoherencia dentro del ámbito cultural de la Europa mediterránea ${ }^{53}$. Los estudios generales de Utrero para los sistemas de abovedamiento hispanos y de Moreno para los monasterios mediterráneos así lo confirman ${ }^{54}$. Por su parte Sastre, con su estudio de los altares hispanos, demuestra el cambio de sus tipos en correspondencia con el de los arquitectónicos y el de las liturgias antes y después del $711^{55}$. Sus reflexiones apuntan además a otra consideración de carácter metodológico, a la superación de la utilización del paralelo como método de análisis. Son los sistemas técnicos y estructurales, incluso formales, lo que denominamos "ambientes técnicos" ${ }^{56}$, y no los paralelos, los que permiten encuadrar culturalmente los edificios.

Desde el punto de vista de los fundamentos y métodos del conocimiento científico, epistemológicamente, se debe considerar hasta qué punto la incoherencia del dato "dendrocronológico" supone en realidad una inconsistencia, y no una refutación, de nuestra explicación, global y coherente. Cabe dedicar el esfuerzo a reconocer cuánta base empírica explica mejor uno que otro de los paradigmas opuestos, al margen de las inconsistencias que ambos contienen.

53 M. Á. UTRERO AGUDO, "Las iglesias cruciformes del siglo VII en la Península Ibérica. Novedades y problemas cronológicos y morfológicos de un tipo arquitectónico", en L. CABALLERO, P. MATEOS y M. Á. UTRERO (edits.), op. cit; 2009, pp. 133-154. Idem, "Late-Antique and Early Medieval Hispanic Churches and the Archaeology of Architecture: Revisions and Reinterpretation of Constructions, Chronologies and Contexts", Medieval Archaeology, 54 (2010), pp. 1-33.

54 M.Á. UTRERO AGUDO, Iglesias tardoantiguas y altomedievales en la Península Ibérica. Análisis arqueológico y sistemas de abovedamiento, Anejos de AEspA, 40, Madrid, 2006. F. J. MORENO MARTÍN, La arquitectura monástica hispana entre la Tardoantigüedad y la Alta Edad Media, BAR Internacional Series 2287, Oxford, 2011.

55 I. SASTRE DE DIEGO, El Altar en la Arquitectura Cristiana Hispánica. Siglos $V$-X. BAR International Series, Oxford, e.p.

56 G. BIANCHI, "Trasmissione dei saperi tecnici e analisi dei procedimenti costruttivi di età medievale", Archeologia dell'Architettura, 1 (1996), pp. 53-64, p. 53, entendido como grupo con un conocimiento tecnológico determinado por M. Á. UTRERO, op. cit, 2006, p. 199. Sobre el problema del paralelo, Ibídem. pp. 197-208 e Idem, "Producción arquitectónica y decorativa cristiana en la Península Ibérica, siglos VIX. Cambio tecnológico y canales de transmisión”, Cruce de Culturas. Arquitectura y su ornamentación y decoración en la Península Ibérica (siglos VI-X/XI), Im Schnittpunkt der Kulturen, Universidad de Heidelberg, 2009, Heidelberg, e.p. L. CABALLERO y F. J. MORENO, "Sobre la dimensión epistemológica e histórica de una propuesta historiográfica. El modelo explicativo mozarabista", en Cruce de Culturas, op. cit., e.p. 